\title{
Urban Sustainability Audits and Ratings of the Built Environment
}

\author{
Constantinos A. Balaras ${ }^{1, * \mathbb{C}}$, Kalliopi G. Droutsa ${ }^{1}$, Elena G. Dascalaki ${ }^{1}$, \\ Simon Kontoyiannidis ${ }^{1}$, Andrea Moro ${ }^{2, *}$ and Elena Bazzan ${ }^{2}$ \\ 1 Group Energy Conservation, Institute for Environmental Research and Sustainable Development, \\ National Observatory of Athens, GR-15236 Athens, Greece; pdroutsa@noa.gr (K.G.D.); \\ edask@noa.gr (E.G.D.); skonto@noa.gr (S.K.) \\ 2 iiSBE Italia, International Initiative for a Sustainable Built Environment, I-10138 Torino, Italy; \\ elena.bazzan@iisbeitalia.org \\ * Correspondence: costas@noa.gr (C.A.B.); andrea.moro@iisbeitalia.org (A.M.)
}

Received: 16 October 2019; Accepted: 4 November 2019; Published: 7 November 2019

\begin{abstract}
Buildings and the built environment in cities are seen as both a source of, and solution to, today's economic, environmental and social challenges. The audit process to collect data and rate their sustainability levels is a demanding process given the complexity of the issues involved. Stakeholders often lack advanced knowledge on the sustainability issues involved, access to practical tools that match the local priorities and the overall resources to diagnose and evaluate the current state, analyse, assess and rank different scenarios, and monitor implementation and progress towards meeting sustainable development goals and local priorities. A new multicriteria European built environment assessment method that is supported by practical tools was developed in a transnational collaborative effort to support the assessment, planning, monitoring and overall decision-making process for rating the sustainability at the building or neighbourhood scale. The assessment system addresses the main sustainability issues (e.g., site and infrastructure, urban systems, energy and natural resources, emissions and environment, service quality, social aspects, economy), which are described and quantified with an "exhaustive" list of $~ 180$ sustainability criteria and indicators, and a manageable number of common mandatory key performance indicators. The assessment system can satisfy the public administrations' needs for being easy to use, open access, flexible and adaptable tools in order to facilitate their efforts for developing effective sustainability plans.
\end{abstract}

Keywords: sustainability; buildings; neighbourhoods; decision-making process; key performance indicators; KPIs; built environment; audit; assessment tools

\section{Introduction}

The European buildings sector represents $41.7 \%$ of the total annual final energy in the European Union Member States (EU-28) or 442 million tonnes of oil equivalent (Mtoe) in 2017 (Figure 1), and is responsible for $\sim 30 \%$ of the total carbon dioxide emissions [1]. During their life cycle, buildings also use half of all raw material extraction and a third of all water consumption [2]. Furthermore, the waste stream from the construction of buildings and civil infrastructure, demolition, road planning and maintenance (i.e., construction and demolition waste-CDW) is one of the heaviest and most voluminous waste streams that accounts for $25 \%$ to $30 \%$ of all waste generated in the EU-28 [3]. 


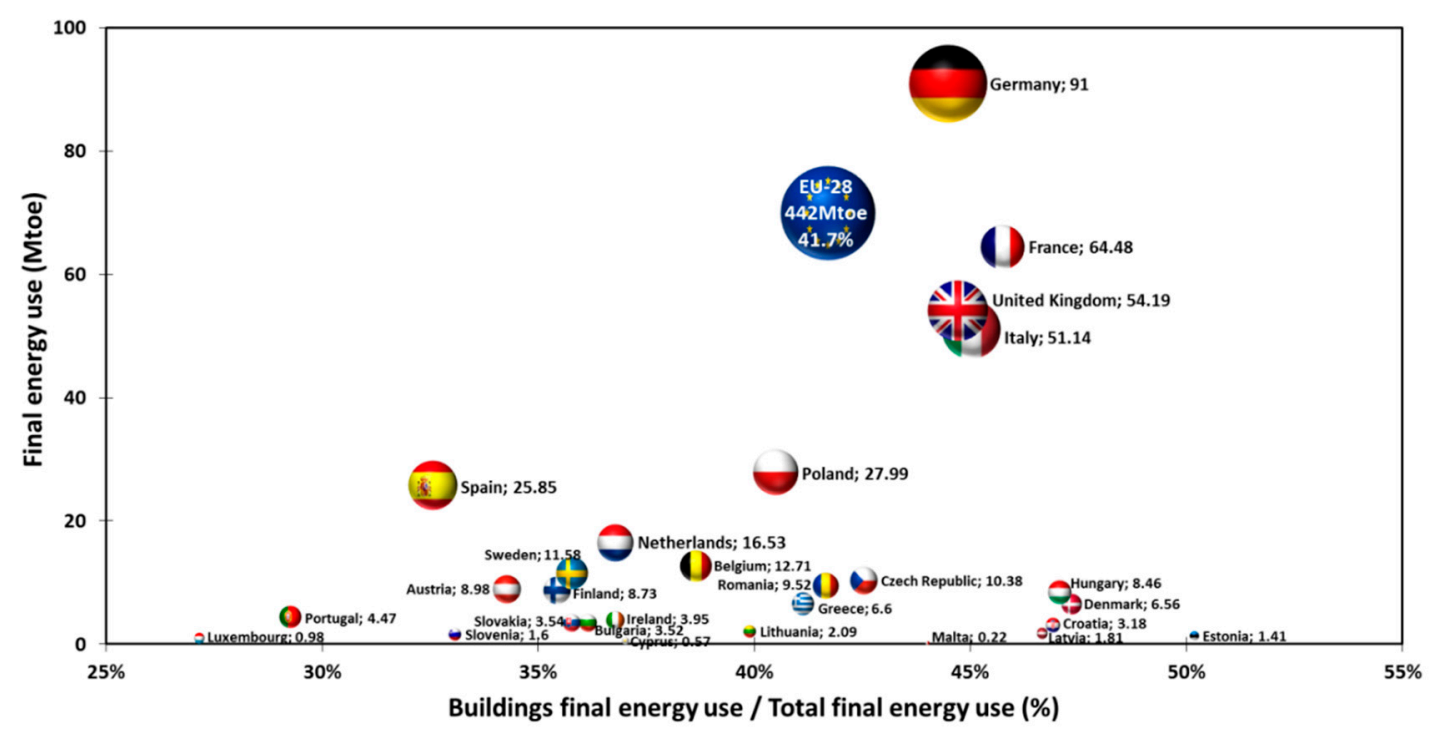

Figure 1. Final energy use (million tonnes of oil equivalent-Mtoe) in European buildings and ratio (\%) of the buildings' final energy consumption to the total. The bubble size represents the total final energy use in each country; for EU-28, the value is not to scale. Data source: Eurostat.

According to the European Commission's urban development network, the European urban areas are home to over two-thirds of the EU's population and account for about $80 \%$ of the final energy use [4]. These urban areas are the engines of the European economy, but they are also places where persistent problems, such as unemployment, segregation and poverty, are most evident. Urban development is central to the EU's Regional Policy, which addresses the environmental, economic, social and cultural dimensions. An integrated approach is necessary in order to achieve sustainable urban renewals or new developments by incorporating environmental protection, education, economic development, social inclusion through strong partnerships between local citizens, civil society, industry and various levels of government.

Recognizing the importance of buildings and the built environment, the EU has initiated ambitious efforts to minimize the use of energy and natural resources in buildings, with radical resource efficiency and circular material flows in its Circular Economy Action Plan [5] to alleviate their environmental impacts. The $2030 \mathrm{EU}$ climate and energy framework includes binding targets and policy objectives for reducing the greenhouse gas (GHG) emissions by at least 40\% from 1990 levels, for increasing the share of renewables by at least $32 \%$ of final energy consumption, and for improving energy efficiency by at least 32.5\% [6]. Member States are also obliged to adopt integrated National Climate and Energy Plans (NECPs) for the period 2021-2030 and develop national long-term strategies to ensure consistency with NECPs. One of the main instruments for addressing these challenges and the energy use in buildings is the Energy Performance of Buildings Directive (EPBD), recently amended by EU 2018/844 that entered into force on 9 July 2018, an integral part of the "Clean Energy for All Europeans" package [7]. EPBD encourages energy efficiency and promoting cost-effective building renovations, with the vision of a decarbonised building stock by 2050. As we move into the new era of nearly-zero-energy buildings (nZEB) as of January 2021, the next big challenge is the renovation of national building stocks. These large-scale efforts could best be served by addressing groups of buildings in urban neighbourhoods, considering synergies and energy interactions between individual buildings and the broader energy system at local level, towards the concept of zero-energy districts [8]. Although the evolution towards energy and spatial planning is challenging, good practices promoting bottom-up initiatives are emerging, focusing on neighbourhood scale oriented urban projects, using decentralised energy systems, local energy communities, energy districts, etc. [9]. 
The EU was also instrumental in shaping the global 2030 Agenda and the United Nations Sustainable Development Goals (SDGs) [10] and is a frontrunner for the long-term implementation of the SDGs that are further enhanced with EU's policies and integrated into all the Commission's priorities [11]. The 17 SDGs are the blueprint to achieve a better and more sustainable future for all, addressing the global challenges we face, including those related to energy, climate and environmental degradation in buildings and cities. The 2030 Agenda integrates in a balanced manner the three pillars of sustainable development-economic, social and environmental.

At the centre stage of the work related to the built environment is SDG-11 aiming to make cities inclusive, safe, resilient and sustainable, targeting sustainable urbanization and transport systems, resource efficiency, mitigation and adaptation to climate change, resilience to disasters, reducing adverse environmental impacts, safeguarding the cultural and natural heritage, and providing green and public spaces. In this context, the supporting goals in the areas of energy and climate include: SDG-7 to ensure access to affordable, reliable, sustainable and modern energy for all, by focusing on increased energy efficiency and the use of renewables for creating more sustainable and inclusive communities and resilience to environmental issues like climate change; SDG-13 to take urgent action to combat climate change and its impacts. Additional goals that are an integral part of sustainable development include: SDG-3 to ensure healthy lives and promote well-being for all by providing and facilitating access to health systems, reducing ambient pollution; SDG-6 to preserve clean water as a natural resource and combat chronic or recurring shortages of fresh water; SDG-8 to promote inclusive and sustainable economic growth, employment and decent work for all; SDG-9 to build resilient infrastructure, promote sustainable industrialization and foster innovation, including transportation, energy and information and communication technology; SDG-10 to reduce inequality by paying attention to the needs of disadvantaged and marginalized populations; SDG-12 to ensure sustainable consumption and production patterns, by promoting resource and energy efficiency, sustainable infrastructure, and providing access to basic services, green and decent jobs and a better quality of life; SDG-15 to combat desertification, halt and reverse land degradation, halt biodiversity loss in relation to urban growth; SDG-16 to promote just, peaceful and inclusive societies for sustainable development in an urban context; SDG-17 to facilitate inclusive partnerships between governments, the private sector and civil society, built upon principles and values, a shared vision, and shared goals that place people at the centre, at the global, regional, national and local level.

The Urban Agenda for the EU was launched in May 2016 with the Pact of Amsterdam as a new multi-level working method promoting cooperation between Member States, cities, the European Commission and other stakeholders in order to stimulate growth, liveability and innovation in the European cities and to identify and successfully tackle social challenges [12]. According to the first-ever SDG index and dashboards report for European cities that was recently released, no European capital city or large metropolitan area has yet fully achieved the SDGs [13]. As illustrated in Figure 2 major challenges lie ahead. The SDG agenda may not be fully achieved without the involvement of cities. Addressing unsustainable patterns of consumption and production, and climate change and environmental degradation, extreme poverty, unemployment and socio-economic disparities, mandates the engagement of regional and local authorities. Overall, cities in Europe perform best on SDG-3 (Health and Well-Being), SDG-6 (Clean Water and Sanitation), SDG-8 (Decent Work and Economic Growth) and SDG-9 (Industry, Innovation and Infrastructure). By contrast, performance is lowest on SDG-12 (Responsible Consumption and Production), SDG-13 (Climate Action) and SDG-15 (Life on Land). As expected, the definition of territorial levels and metropolitan areas and standardize subnational data and indicators, revealed major gaps in available information in order to monitor all the SDGs. 


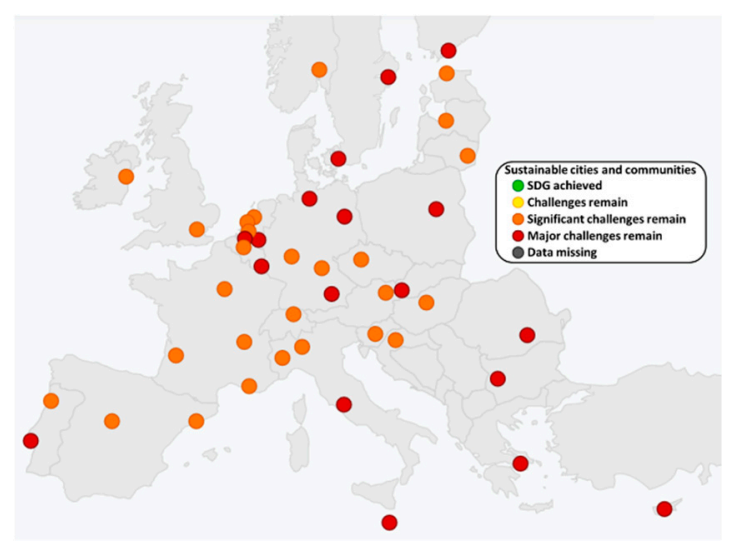

(a)

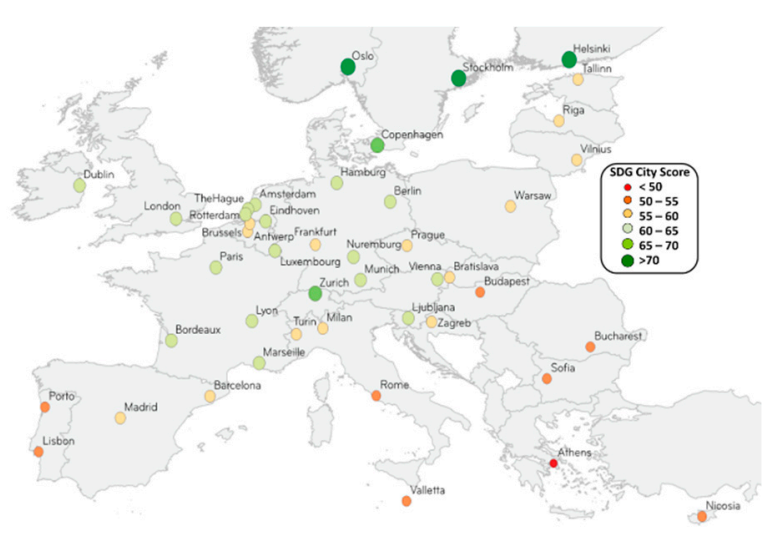

(b)

Figure 2. (a) European cities Sustainable Development Goals (SDGs) index for sustainable cities and communities (SDG-11); (b) overall SDG city scores. Source: https://euro-cities.sdgindex.org.

The various aspects of sustainable development in an urban context include energy, environment, transportation, infrastructure and services, land use, natural resources, and social well-being among others, as well as mandating specific actions and significant efforts. The SDGs are further enhanced through national action plans, with regional level and finally local level priorities and goals. More than ever, a local push is needed to improve sustainability efforts following a bottom-up approach of local actions that will effectively drive the processes to meet the SDGs in the spirit of the concept "Think Globally, Act Locally". However, developing, monitoring and assessing local, regional and national plans towards sustainable development at building and neighbourhood scale, considering the plethora of SDGs and sustainability issues, are complex undertakings. These efforts can be overwhelming for local and regional authorities that may not have the expertise and personnel. Accordingly, there is a need to facilitate local authorities and municipalities to act quickly and accelerate progress.

\section{Existing Systems for Rating and Labelling}

Energy and environmental audits in industry, tourism, commerce and the buildings sector have been used to collect the appropriate data that is essential for a systematic analysis in order to identify, quantify and report on the opportunities for improved performance. There are several available schemes for building energy audits that depend on the project intent and procedure (e.g., energy performance assessment, rating, certification or labelling), the specific operating conditions, the building type, among other factors [14]. The use of the term "energy audit" can be subjective and can vary from country to country since they are conducted in varying degrees or levels of technical detail, accuracy and complexity based on the purpose they serve. In some cases, this is done intentionally to reflect certain attributes, levels of complexity or stand-out in the market as a tailored process to a specific scheme and thus differentiate from other competing processes. Sometimes, it may also be an unintentional result in an effort to directly link required processes to different legal acts and relevant regulations that may apply. Some examples include survey, screening, diagnosis, inspection, review, preliminary (detailed) audit or preliminary (detailed) assessment, or as it relates to financial assessments like an investment-grade audit or feasibility study.

Practically all schemes include some common stages: preliminary contacts (e.g., client interview to define project intent, collect preliminary information), intake (e.g., collect available data like drawings, energy bills or metered data, perform an on-site visit, collect field data, complete checklists, audit forms and protocols, verify estimates and default values, perform in-situ measurements), analysis (e.g., rating, benchmarking, perform calculations or simulations, define a baseline to investigate energy conservation measures and assess scenarios, determine a list of cost-effective recommendations with quantified 
savings), and results (e.g., meet and present results to the client, generate reports and other deliverables). Some schemes may have distinct characteristics (e.g., use specific calculation tools that will determine the input data, or deliver distinct results like an energy performance certificate or prepare documents and specifications for tenders).

Sustainability audits in an urban context are more elaborate since they involve various issues and themes that need to be addressed [15]. Sustainability is also being adopted into building codes at different levels of government and with varying motivations. The approach taken reflects local societal perceptions, political priorities, national policies and economic factors [16]. The creation of standards or codes that define a level of performance for sustainable buildings has emerged as a need within the industry. However, there are different approaches due to wide variations in economic, social, political and technological conditions and priorities in different countries and jurisdictions around the world. Rating systems provide a method that one can voluntarily adopt and comply with various sustainability measures that meet a pre-defined set of requirements. Standards are also being developed as a collection of criteria for meeting the acceptable requirements at a high level of performance. They may be adopted in building codes or simply used as a level of performance that a project may comply by. For example, the ASHRAE Standard 189.1 that is recognized as a leading green standard around the world and forms the technical basis for the International Green Construction Code (IgCC), includes mandatory criteria in several sustainability issues and themes, site, construction, materials, energy, indoor environmental quality, water, etc. [17].

At building scale, various voluntary sustainability rating systems and labelling schemes have been developed, e.g., BREEAM (https://www.breeam.com/), CASBEE (http://cabee.eu/), Green Star (https://new.gbca.org.au/green-star/), LEED (https://new.usgbc.org/leed) and Protocollo ITACA (http: //itaca.org/), to facilitate the process for reducing energy use and environmental impacts during construction, management and operational phases [18]. The systems include different performance indicators that are used as metrics with fixed weighting and scoring systems to determine how well the sustainability objectives are achieved, facilitate the decision-making process, assess specific project requirements or ensure compliance with regulations and norms [19-21]. The indicators quantify what one is trying to achieve, and depending on specific project needs and priorities one may need to use several of them at different stages of the work or process. The indicators can be expressed as numerical values (e.g., building's energy use intensity in order to assess different performances or compare against other benchmarks; water consumption per building occupant, etc.), or ratios and percentages (e.g., percent of renewables that cover power or heat demand; percent of recycled waste, etc.).

A voluntary reference framework known as LEVEL(s) is also being developed for the European Commission [22] providing a common European framework of common indicators to measure the sustainability performance of buildings across their whole life cycle, focusing on GHG emissions, resource efficiency, water use, health and comfort, resilience and adaptation to climate change, cost and value. Each indicator links the building's individual characteristics (currently referring to only residential and office buildings) and impacts to sustainability priorities, facilitating users to consider key concepts and building-scale indicators, following specific guidelines and standardized calculations for each indicator.

Several systems have also been extended to urban scale, e.g., BREEAM Communities, CASBEE for Urban Development, LEED for Neighbourhoods and Protocollo ITACA Urban Scale. The main aspects for sustainable cities address similar performance indicators like the ones for building scale, and include more categories, for example, urban transport, supply and distribution networks, social factors, etc. [23].

A new European multicriteria assessment method has been developed that enhances existing knowhow in a holistic system for accessing urban sustainability of the built environment at neighbourhood scale. This complements the existing public approaches at building and city scales, so that it is more suitable and manageable to handle by municipalities. The following sections outline the main structure of the method and tools for addressing the sustainability issues for buildings and neighbourhoods, the generic framework with an emphasis on the energy and environmental 
indicators, the key performance indicators, the results from nine European pilots, providing details for the application in Greece, and the training system that includes educational material developed for decision-makers and technical professionals.

\section{The Common European Sustainable Built Environment Assessment for Mediterranean Cities (CESBA MED) Method}

The Common European Sustainable Built Environment Assessment for Mediterranean cities (CESBA MED) was a collaborative effort of several European organizations from seven countries. The work is structured around the UN 17 SDGs, aiming to support users and their efforts towards a sustainable future. The initial concept of the assessment method and tool was a reference decision-making process that was originally developed for the building scale [24] and then extended at neighbourhood scale. The following sections outline and briefly discuss the process for converging on the number and type of sustainability indicators that are considered in the method, the normalization and scoring process, the development of the generic framework, and the national tools.

\subsection{Sustainability Indicators and Key Performance Indicators (KPIs)}

The approach taken in this work was to first develop a generic framework that includes an "exhaustive" list of sustainability indicators that cover all relevant themes, given that there is still no consensus on a specific number or types of indicators. This way one can have access to a comprehensive database that includes different performance indicators from which to select the ones that meet local priorities and needs, or best fit the project intent. A minimum number of key performance indicators are defined and used in order to ensure that the core sustainability issues can be addressed in a satisfactory manner.

Accordingly, the first step was to critically review 14 transnational European projects and public assessment systems, in order to derive a representative list of indicators at building and neighbourhood scales that address the main sustainability pillars [25]. A total of 216 indicators were identified, critically reviewed and finally grouped under the main sustainability issues.

The structure of the method organizes the information in Issues, Categories and CriteriaIndicators [26]. The "Issues" identify the general themes that are essential for assessing the sustainability at building and neighbourhood (urban) scales. The sustainability Issues for the building scale include: A-Site and infrastructures, B-Energy and resources, C-Environment, D-Indoor Environmental Quality (IEQ), E-Service quality, F-Social, cultural and perceptual aspects and G-Economy. The seven sustainability Issues for the neighbourhood scale include: A-Urban systems, B-Economy, C-Energy, D-Emissions, E-Natural resources, F-Environment and G-Social aspects.

The "Categories" under each Issue describe its specific aspects that group relevant Criteria and Indicators. Each Issue includes a different number of Categories. The building scale includes 25 Categories. For example, under the issue "IEQ" there are four categories: Indoor air quality and ventilation, Air temperature and relevant humidity, Daylight and illumination and Noise and acoustics. The neighbourhood scale includes 23 Categories. For example, the issue "Energy" includes two categories: Non-renewable energy sources, and Renewable and clean energy sources.

The "Criteria" detail the specific aspects of a Category and represent the main assessment entries used to characterize a building or an urban area. The "Indicators" quantify the performance with respect to each criterion. In principle, several indicators can be associated with the same criterion, since one can define multiple strategies to quantify the building or urban area performance with regard to a specific criterion. For example, building energy use intensity (EUI) can be expressed as $\mathrm{kWh} / \mathrm{m}^{2}$ or $\mathrm{kWh} / \mathrm{m}^{3}$ and in some cases energy use per employee (e.g., for an office building) or energy per bed (for hotels), depending on the characteristic functions of a building. For simplicity in this work, only one indicator is associated with each criterion. The metrics are used to quantify the performance and determine how well the sustainability objectives are achieved. 
Tables A1 and A2 summarize the various sustainability Issues, Categories and Indicators for building scale [27] and neighbourhood scale [28]. Different numbers of criteria-indicators are included under a given category, each one of them describing a particular aspect of the corresponding category. For example, at the neighbourhood scale, Category 'C.2 Renewable and clean energy' includes fourteen Indicators, e.g., share of on-site renewables on total final or primary energy consumption for residential or non-residential buildings, share of electricity production from renewables on public or private property, total electricity from renewables that is exported from the area, total electricity from renewables used in or exported from the area, share of thermal energy from renewables on public or private property, etc.

Some indicators may appear under both scales (e.g., energy use at the building scale and for all buildings in the area at the neighbourhood scale). For example, at the building scale under the Issue 'B. Energy and Resources', the Category 'B.1 Life Cycle Non-Renewable Energy' includes the Criterion 'B.1.2 Final Thermal Energy Use' and 'B.1.3 Final Electrical Energy Use'. Aggregating the relevant information for all the buildings in the area, one can derive the equivalent indicators at the neighbourhood scale (i.e., B.1.1 for each building and C.1.1 for all buildings in the area). Sometimes qualitative criteria are used instead of quantitative ones. In this case, the expert's assessment is based on the prescribed reference descriptions in order to assess and score the specific performance. For example, at the building scale under Issue 'F. Social, Cultural, Perceptual', Category 'F.2 Culture and Heritage' that includes Criterion 'F.2.1 Compatibility of urban design with local cultural values' is qualitatively assessed with an indicator of whether the architectural design features related to the urban design are incompatible, marginally- or fully-compatible. Similarly, at the neighbourhood scale, under Issue 'G. Social Aspects', Category 'G.6 Management and Community Involvement' the Criterion 'G.6.3 Community involvement in urban planning activities' is qualitatively assessed with an indicator that reflects different levels of citizens' engagement in the planning process, from a non-participatory process (to reflect performance below standard) to full co-decision with delegated citizen power (to reflect an ideal performance).

A limited number of key performance indicators (KPIs) were selected from the various indicators as mandatory minimum requirements in order to be able to address the main sustainability issues, which are also identified in Tables A1 and A2. For example, one commonly accepted metric to measure a building's energy use performance is the energy use intensity (EUI in $\mathrm{kWh} / \mathrm{m}^{2}$ ), which can be used to benchmark against similar buildings or with best-practices and assess energy efficiency measures within buildings. The KPIs are defined and calculated following common standardized procedures. This work considered most of the LEVEL(s) indicators in the process of selecting the KPIs for the building scale. The results from the normative KPI calculations can then be used as a passport for comparing different buildings, areas, regions or countries, on a common basis.

The organization of the sustainability issues, the selection of the most applicable criteria, performance indicators and KPIs followed an iterative process at various stages of the work. The first step was to review, analyse and organize the knowhow generated from $14 \mathrm{EU}$ projects and systems [25] and the work in the new LEVEL(s) indicators [29]. Each national team of the CESBA MED partnership engaged and collaborated with local committee experts in six EU countries to elaborate the issues and indicators, in order to ensure that they are representative and cover national needs and priorities in local context.

For reaching a wider consensus, the work progress on the performance indicators and the proposed KPIs were also reviewed and elaborated with other European experts and project representatives during two sprint workshops. The final list of the KPIs for building and neighbourhood scale was fixed following the nine national pilot tests performed by the partners in six EU countries. As a result, some KPIs were excluded due to the limited availability of the input data, e.g., quantities of building construction materials and recyclable content that have been used for existing buildings or other public works in the area, thus ensuring the applicability of the approach and the use of the indicators in the field. 


\subsection{Normalization and Scoring}

All sustainability assessment and rating systems use a normalization process in order to convert the indicator values into a common basis (scale). The various indicators are diverse in nature, have numerical values with different orders of magnitude and correspond to physical quantities with different units or in some cases include qualitative scores. The normalized scores of the individual indicator values are then aggregated using different weights to calculate a score for the corresponding categories and issues, and finally a total sustainability score for a building or a neighbourhood.

\subsubsection{Indicator Scores}

Each indicator value is a dimensionalized and rescaled value (Figure 3) in an interval from -1 (performance below standard) to +5 (advanced performance) [26], following a similar concept with Protocollo ITACA [30]. For example, the score value at "0" corresponds to the minimum acceptable performance of an indicator in compliance with minimum standard regulation mandates defined by law (e.g., an EUI for new buildings or the percentage use of renewables), or the value of current practice in case of no regulations (e.g., percentage of employment, length of pedestrian and bicycle paths). The score value at " +5 " corresponds to excellence or ideal performance (e.g., an EUI for a nearly zero energy building, or very-high employment rate for the residents in a neighbourhood). Values of indicators below minimum standards or current practice are assigned to a score of " 1 ".

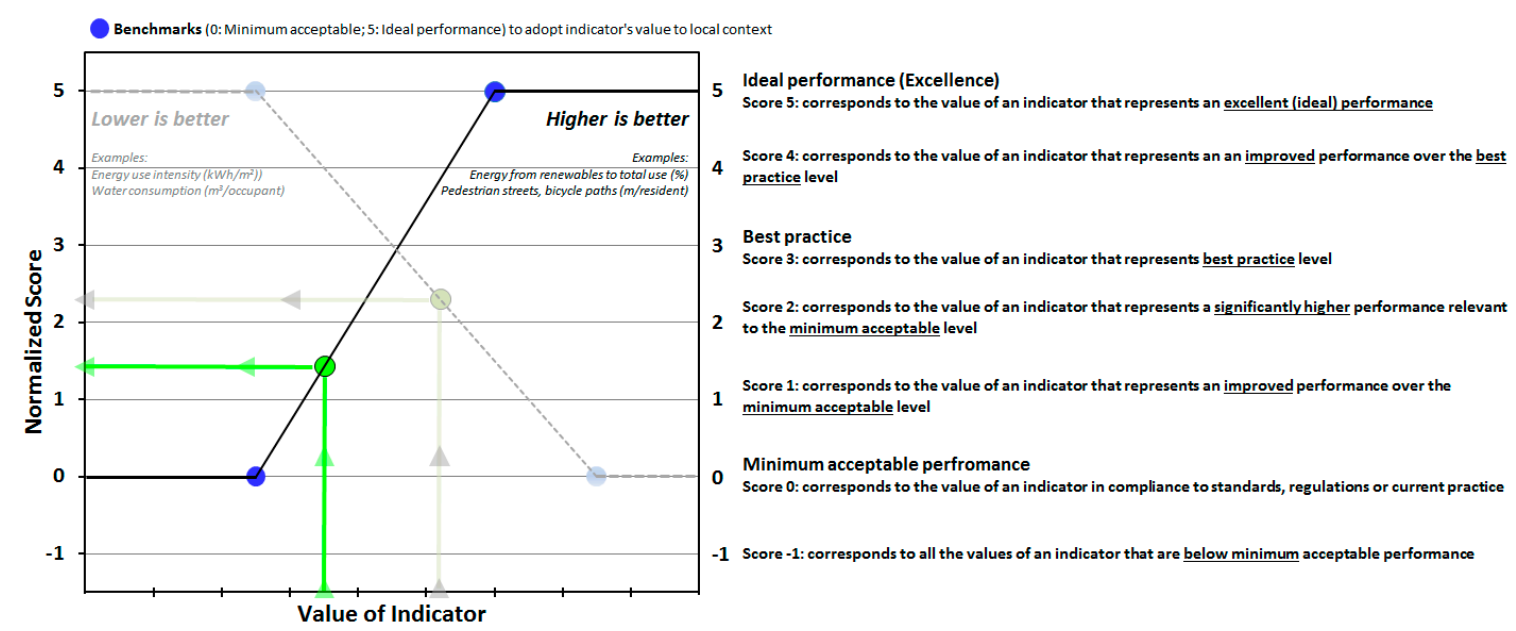

Figure 3. Normalizing and scoring process. For an indicator following the principle "higher is better," the linear correlation is illustrated with the black solid line, while the principle "lower is better" is illustrated with the grey dashed line.

For simplicity, individual scores are defined by linear interpolation between the two limits (i.e., " 0 " and " +5 "). For each indicator, the numerical values at the two limits are adapted to the local context by using appropriate national, regional or local benchmarks. For some indicators, higher performance corresponds to a higher normalized score, following the principle that "higher is better", thus the slope of the linear correlation (from 0 to +5 ) is positive (e.g., the percentage use of renewables, the length of pedestrian and bicycle paths in a neighbourhood). In this case, a higher value of the indicator corresponds to higher performance and thus it receives a higher normalized score. For others, the normalized score follows the principle that "lower is better" (e.g., a low EUI for buildings or low water consumption), thus the linear correlation (from 0 to +5 ) has a negative slope. In this case, a lower value of the indicator corresponds to higher performance and thus it receives a higher normalized score. 
The national and local benchmarks for each indicator have been predefined at the appropriate values for (ideal) excellent practice (corresponding to " +5 " in the normalized score), the minimum acceptable performance (corresponding to " 0 ") and below standard (corresponding to " -1 "). These values are already included in the national and local versions of the method (see Section 3.1). If necessary, the user can adjust them according to the local characteristics (e.g., energy use intensities for the local buildings, water consumption in the area, etc.).

\subsubsection{Sustainability Score}

The calculations for the sustainability score are weighted in terms of the regional, local or project priorities. The weighting factors are properly estimated values that reflect the relative importance of characteristics compared to others. This way, the user has an opportunity to place the desirable emphasis on specific sustainability issues and performance indicators, to reflect regional variations and add local context. The weighted score of each Indicator is calculated by using different multiplicative factors to adapt its normalized score (see Section 2.2.1) as illustrated in Figure 4a. The following discussion reviews the various weighting factors that are taken into account at different stages of the calculations, starting at the overarching level of the sustainability Issues and then at the more detailed level for addressing the characteristics of each indicator.

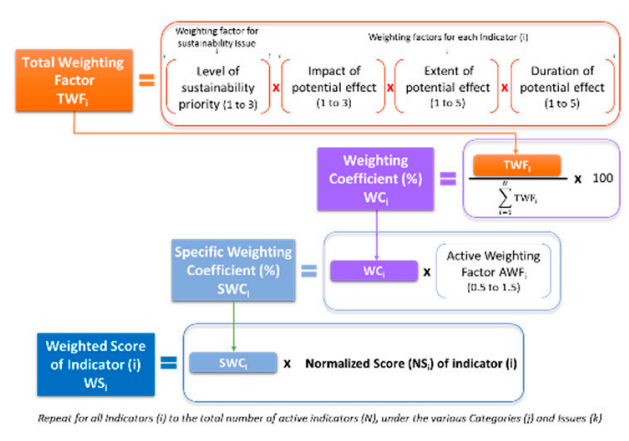

(a)

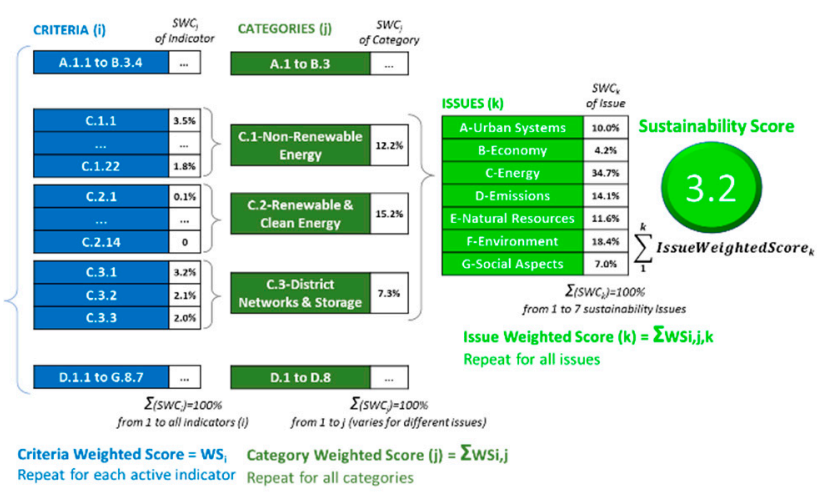

(b)

Figure 4. Overview of the calculation processes at the neighbourhood scale for the: (a) Indicator's (i) weighted score; (b) weighting allocation and aggregation of scores for Criteria, Categories, Issues and sustainability score. For illustration purposes, the active indicators are identified with a numerical value, while for the inactive indicators (not selected), the specific weighting coefficients are shown as 0 . The graphic does not include all the criteria and categories that are listed in Table A2.

For each one of the seven sustainability Issues, it is possible to define its level of priority on a scale from 1 (less important) to 3 (most important or more relevant). For example, the level of sustainability priority for the energy issue may be set at 2 (i.e., considered of average importance if the buildings have an average energy performance and good exploitation of renewables), while the issue of emissions in an area with major environmental problems the assigned priority may be set at level 3 (i.e., considered a major issue).

Beyond the mandatory KPIs, one can select an appropriate number of active indicators that best fit the local needs and project-specific priorities under each Category and Issue. As a default, the weighting factors are equally distributed among the active indicators so that the weightings equal $100 \%$. These coefficients may then be adjusted to place more emphasis on a specific indicator.

The total weighting factor $\left(\mathrm{TWF}_{\mathrm{i}}\right)$ for each indicator (Figure $\left.4 \mathrm{a}\right)$ is calculated as the product of the following weighting factors that account for the:

- Level of sustainability priority for the Issue that includes the specific indicator, which is rated using a 1 to 3 points scale described above, and for each Indicator the: 
- Impact of potential effect, rated using a 1 to 3 points scale, i.e., 1-minor, 2-moderate, 3-major),

- Extent of potential effect, rated using a 1 to 5 points scale depending on the spatial coverage, i.e., 1-block, 2-neighborhood, 3-district, 4-urban/region, 5-global),

- Duration of potential effect, rated using a 1 to 5 points scale, i.e., 1 for 1 to 3 years, 2 for 3 to 10 years, 3 for 10 to 30 years, 4 for 30 to 75 years, 5 for greater than 75 years).

For example, based on the above, the global warming potential indicator (C.1.3 at building scale, Table A1) the Issue (C-Environment) can be weighted with 3 (i.e., the environment is considered a major issue), and assigning for the indicator a weighting factor of 3 (major impact), 5 (global potential effect) and 5 (duration $>75$ years). The on-site use of renewables in buildings (C.2.1 at neighbourhood scale, Table A2), the Issue (C-Energy) can be weighted with 2 (i.e., energy is considered an average issue in an area where all buildings use solar collectors), and assigning for the indicator a weighting factor of 3 (major impact), 2 (neighbourhood potential effect) and 3 (duration 10 to 30 years). Since the specification of these weighting factors is not a trivial process, the national versions of the method (see Section 3.1) include national default values, although a user can always adjust them.

The weighting coefficient $\left(\mathrm{WC}_{\mathrm{i}}\right)$ that accounts for the relative importance of an indicator among the selected ones is calculated as a percentage of the ratio of the individual $\mathrm{TWF}_{\mathrm{i}}$ to the total for all active indicators (Figure 4a). To further fine-tune the weighting coefficients, the values may be adjusted using another multiplicative factor to account for the possible importance of an indicator in the context of a specific project or its potential impact on more than one criterion, categories or even under different issues. The active weighting factor (AWF) is set at 0.5 (i.e., lowering the Indicator's weight by half) or 1.5 (i.e., increasing its weight by half). For example, the AWF for C.1.20 Energy use for public lighting (Table A2) can be set to 1.5 (i.e., $50 \%$ more important) because of its importance in a project not only in terms of energy savings, but also in relation to the perceived safety of public areas (G.8.3) and even aesthetics (G.8.7). Finally, the normalized score of each indicator is multiplied by the specific weighting coefficient (SWC) to obtain the weighted score (WS) of each indicator.

Overall, the process provides the ability to use different weights for adjusting each indicator (criterion), category and issue, according to local environmental, social and economic priorities and scenarios under assessment. Although altering the weighting system may be perceived as a manipulation of the results in order to improve the overall scores, the intent is to allow sufficient user flexibility for adapting the method to the local and project-specific priorities. Alternatively, to safeguard the process, the default weights can be reviewed, agreed upon and then locked by the decision-makers, before allowing third party interaction.

The normalized scores associated with all active indicators (criteria) in the same category, e.g., are aggregated to produce a single weighted score for each category. For example, the criteria weighted scores for C.1.1 up to potentially C.1.22, C.2.1 up to C.2.14 and C.3.1 to C.3.3 at neighbourhood scale (Table A2) are used to obtain the category weighted scores for C.1, C.2 and C.3, shown in Figure 4b. Then, the scores for all categories in the same issue are further aggregated to produce a single weighted score for each issue (e.g., C-Energy in Figure 4b). Finally, the results from all seven issues are aggregated to produce a concise total sustainability score for the project.

\subsubsection{The Generic Framework}

The CESBA MED Generic Framework (GF) is the general, all-inclusive starting version of the tool that supports the assessment method with all seven issues, categories and indicators available for the building and neighbourhood scales (Tables A1 and A2). The total number of indicators in the GF that one can potentially select from and use is 153 for the building scale [27] and 178 for the neighbourhood scale [28]. This "exhaustive" list of performance indicators is an excellent starting point for developing national and local tools by selecting and using only the ones that are relevant according to national, local sustainability priorities and project intent. For practical purposes, one should select a manageable number of indicators from the complete list under the various issues and categories that for a given project best match the local sustainability issues, priorities and strategic policies. During the 
development of the national tools (see Section 3.1) this exercise was elaborated for adapting the GF Tools in six national versions and then to local context during the specific pilot projects. Always, the minimum number of indicators are the key performance indicators that were determined as a result of the iterative process for developing the CESBA MED GF that finally reached 13 KPIs for the building scale [31], including most of the LEVEL(s) indicators, and 16 KPIs for the neighbourhood scale [32]. The KPIs are collected and stored in a "Passport" that constitutes a depository of common and comparable data. The two-page CESBA Passport provides some general information on the project and details the KPI values. These results enable a consistent comparison of the key information on the sustainability performance of buildings and neighbourhoods for exchanging and sharing information and good practices between different areas, cities, regions and countries. A single page CESBA Certificate is a concise single-page information sheet that captures the scores for each of the seven sustainability issues and can be used to display and communicate the overall performance.

\subsubsection{The GF Tools}

All the indicators are analytically presented in the building and neighbourhood scale GF tools. The presentation of each indicator (Figure 5a) includes background information, an overview of relevant calculation steps that one must follow for KPIs (according to standards) and for others based on recommended good practices that may be adapted according to national or local practices. Supporting references and other resources are also included and the user may also write-in other relevant notes. The input is the calculated value for the corresponding indicator (e.g., the energy use intensity in $\mathrm{kWh} / \mathrm{m}^{2}$ ) for the specific project. Under the assessment criteria, the tool automatically transfers the default benchmark values that correspond to the scale $(-1,0,3,5)$. These values may be further adjusted, if necessary, in order to accommodate for some specific characteristics for a given project (e.g., adjust the energy use intensity benchmarks for historic buildings that may not strictly comply with conventional high-performance standards). Entering the numerical value of the indicator, the tool estimates a weighted score. The user may also include a target performance value for reference and comparative assessment. As an option, there is also a place holder for a third-party score that can be used during verification.

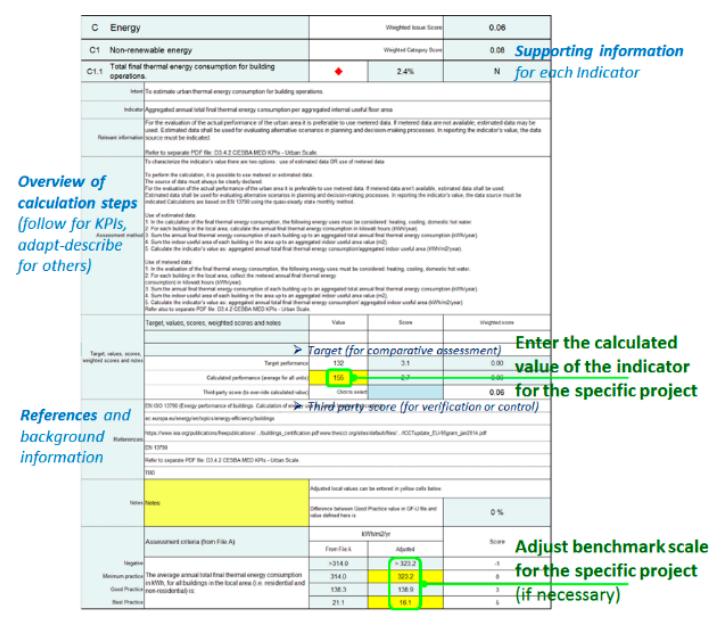

(a)

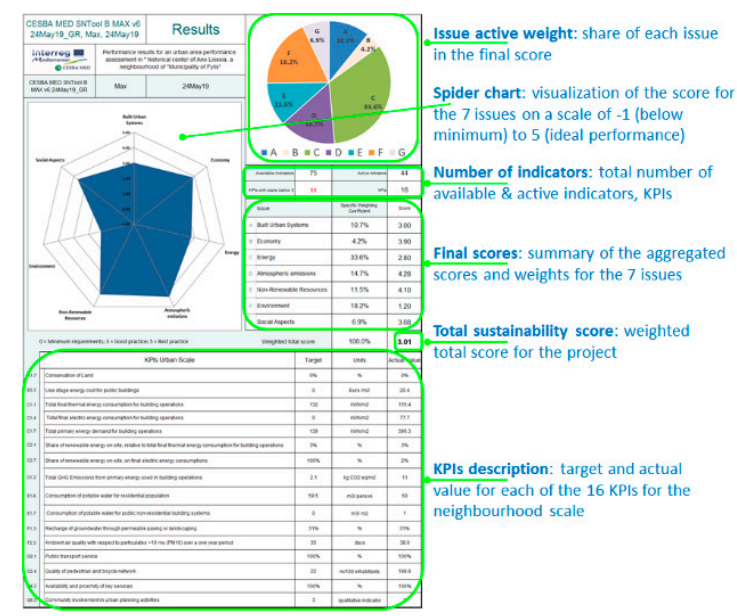

(b)

Figure 5. Excerpts from the Generic Framework (GF) tool: (a) Presentation an indicator and interface for benchmarking and scoring; (b) overview of the main final results.

The final results (Figure $5 b$ ) summarize the performance assessment for the building or the urban area, along with insights on the importance of the different issues in the final score, number of active indicators and detailed overview of the KPIs. The specific scores for each one of the seven sustainability issues are listed and are also illustrated in a spider chart to easily understand and communicate results, 
by identifying the sustainability issues with strong performance (scores close to 5) or the weaker ones (scores close to 0 ) and the total sustainability score for the project. A detailed presentation of the results for each one of the KPIs includes the corresponding target and actual value.

\subsection{The Decision Making Process}

The CESBA MED Tools are intended to support decision-makers and managers of public and municipal building stocks in the implementation of more sustainable renovation plans or the new developments, combining the building and the neighbourhood scales [33]. The process should consider the buildings in their urban environment and look for synergies between groups of buildings in the area in order to optimize energy planning in the context of a sustainability performance assessment.

The CESBA MED method and tools (Figure 6) can support all project phases. Instrumental in the whole process is the engagement of the people. Urban developments affect a wider community of citizens, workers, commuters, visitors, etc. Therefore, it is essential that all affected parties, including residents and businesses, are actively involved in all stages of the process, from the early diagnosis, for shaping the developments that affect them. Empowering local communities through regular and meaningful consultations and engagement, improves transparency through more open governance and greater public participation of citizens and other local stakeholders and helps reach greater public acceptance through a sense of ownership.

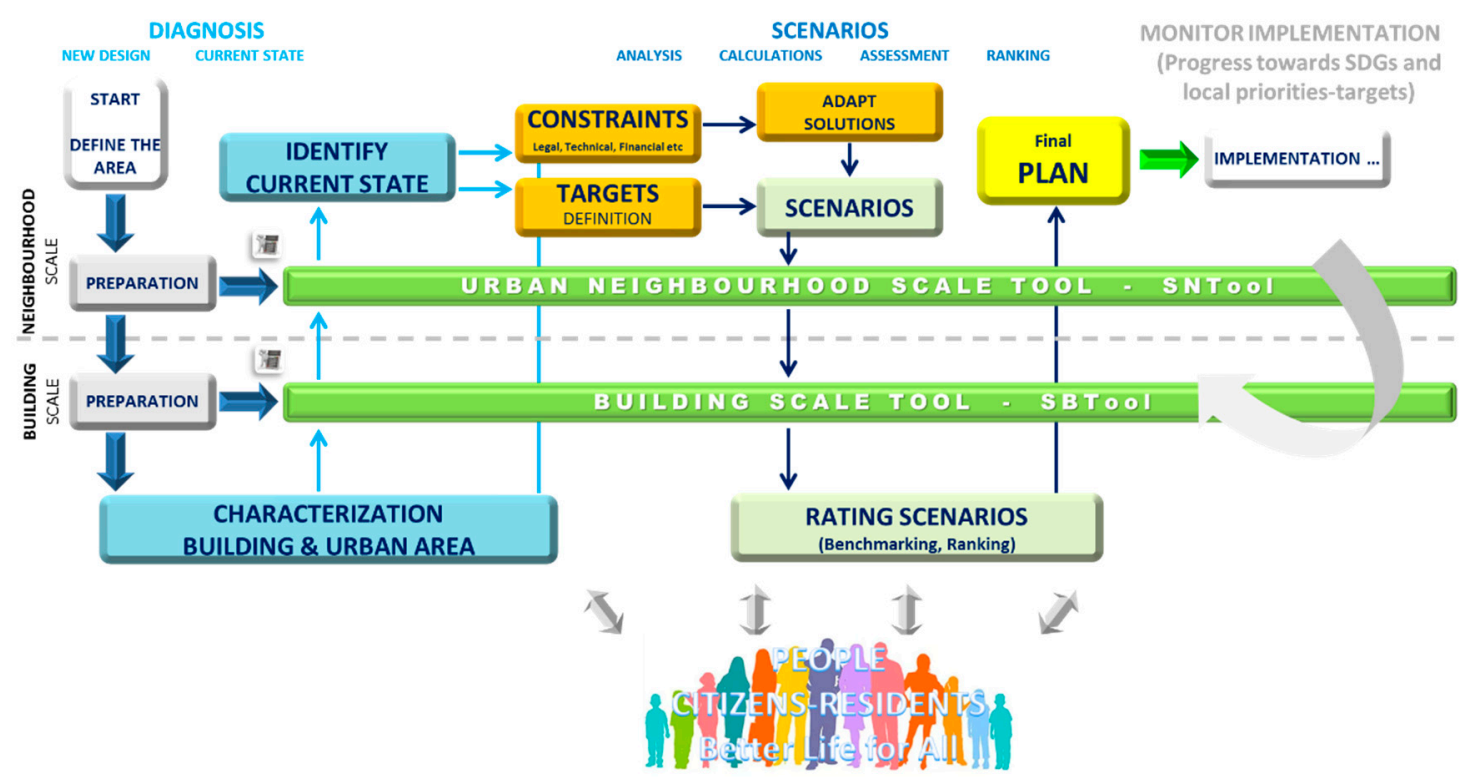

Figure 6. Schematic of the main stages and overall decision-making process.

Assessing the actual performance at the current state takes a snapshot of the existing condition and characteristics, and identifies the critical sustainability issues. Accordingly, one can assess the potential performance resulting from the implementation of different renovation scenarios in order to identify the most cost-effective and sustainable one. Similarly, for new developments, it is possible to assess the potential performance of alternative planning options in order to identify the most cost-effective sustainable development scenario. In both cases, after implementation, it is possible to monitor and evaluate the progress at different stages, the effectiveness of implemented actions and the achievement of the sustainability performance targets.

\subsubsection{Diagnosis}

The first step is to define the physical boundaries and decide which of the surrounding infrastructures are relevant. The physical boundaries of the urban area may be derived considering the spatial coverage along with the legal and administrative lines, the property ownership status and land 
use, the social and economic characteristics of the area, the period of building construction and the energy supply infrastructure, etc. The neighbourhood of a small urban scale area (e.g., block/cluster of buildings) may include $5-15$ buildings with a traditional composition extending over $200-400 \mathrm{~m}$ in size that can be crossed in 10-15 min walk, with 200-1500 inhabitants.

During the preparation phase, the appropriate input data is collected in order to create a sufficient knowledge basis. Like in every audit process [14] it is essential to collect good quality data is essential, since this will have a direct impact on the overall quality of the process and it is critical for securing accurate and realistic final results for quantifying the respective indicators. Sometimes specific characteristics cannot be determined or measured in a practical way with an acceptable cost, at least for routine audits, while even the perception of building or neighbourhood characteristics can deviate significantly from one assessor to the other. Accordingly, it is crucial to find the right level of simplification so that the audit and data processing is time-efficient while obtaining results that are close to the most detailed analysis as possible.

Accessibility to reliable data and information is indispensable to adequately assess the sustainability performance of the urban environment. This will allow the adoption of good monitoring practices, resulting in better policy formulation and implementation. In general, data acquisition may be time-consuming. Information may be scattered among different administrative bodies of the municipalities and other organizations (e.g., building authorities, cadastral office, land surveying office) and other resources like census data, municipality and regional reports (e.g., operational programs), existing energy performance certificates, energy supply companies, along with publicly accessible resources (e.g., Google Earth, Open Street Map), etc. In all cases, a site visit will be necessary in order to perform field inspections of the buildings and the neighbourhood and to collect missing data or verify and extend available information.

Educated assumptions or use of default values may be needed for quantifying some indicators. However, one must consider the trade-offs between the effort involved to measure specific data; what accuracy can be reached, how much effort will be involved, how much time will be required and what is the relevance or impact on the results. With the exception of the calculations for the KPIs that follow specific normative procedures according to standards, the final decision depends on the relevant expertise and past experience of the user/assessor. In any case, one needs to be aware of the uncertainties or inaccuracies involved in a given process as a result of the assumptions that will be made or imposed by specific calculation procedures and the ways to interpret and use the results.

\subsubsection{Scenarios}

As a first step, the information collected during the diagnosis is used for a SWOT analysis. This way one can prepare more applicable scenarios that will exploit the area's main strengths and opportunities in terms of sustainability and take corrective measures that are responsive to its weaknesses, while accounting for legal-technical-financial-environmental constraints that may limit the range of possible retrofit strategies. Legal constraints may result from building codes, mandates for improving the energy performance of buildings, and cultural heritage protection regulations. Technical constraints may limit the use of some technologies in building renovations, e.g., space availability for on-site installation of renewables on building rooftops or facades or near-by areas. Financial constraints are often the largest obstacles in renovation projects. Available funding sources must be secured early in the planning phase, taking advantage of different financing instruments. For building renovations, one needs to consider the financial status of the building owners, as well as the tenants, in order to avoid negative social impacts like gentrification. Environmental constraints are usually related to the local climatic conditions which may not favour some technologies or the exposure of building roofs and facades to solar radiation for the proper exploitation of thermal solar or photovoltaics. 
Early in the process, one must define clear and measurable targets that should be achieved by the project, covering all main aspects of sustainability, e.g., environment-energy, economy and social. The targets must be SMART, i.e., Specific (clearly defined), Measurable (quantifiable), Attainable (realistic and achievable), Relevant (for energy retrofitting of urban districts) and Time-bound (with a specific time plan of when they can be achieved). Environmental targets should consider the means to improve energy performance, reduce GHG emissions, increase the share of renewables, prioritize the use of sustainable materials, reduce soil sealing and increase open natural areas. Targets related to the economy should consider means to improve return on investment, exploit the use of different instruments for financing, maintain affordable property and value of land, secure resources to strengthen economic feasibility and secure sustainable growth and enhance local labour force participation. Social targets should avoid gentrification that may result from energy renovations, improve district surroundings (e.g., open spaces, accessibility, heat island), improve transport infrastructure and mobility, encourage community involvement and citizen's engagement in near- and long-term planning, strengthen public services and improve safety and security.

The scenarios for improving the performance of a neighbourhood should consider all the buildings in the area and seek synergies and opportunities to increase energy performance by prioritizing central energy supplies and district energy systems versus individual solutions, use environmentally friendly materials, enhance open green public spaces, improve public transport and mobility and improve public infrastructures. At the building scale, the priority is to improve energy performance of public buildings, reduce energy use and emissions from non-renewables, integrate renewables (e.g., consider thermal solar for domestic hot water or combi systems, use photovoltaics with appropriate energy storage and/or smart grids), expand central energy supply (e.g., natural gas network) and increase energy efficiency by prioritizing central energy networks over individual solutions. Engaging the citizens and building occupants in the process can provide valuable input to the experts and technical teams.

Different scenarios are evaluated along the following lines: (a) Selecting and optimizing energy renovations at a building and neighbourhood scale (i.e., reducing energy demand, increasing energy performance by prioritizing central energy supplies versus individual solutions, integrating renewables with appropriate energy storage and/or smart grids); (b) considering other interventions for improving public transportation and mobility, enhancing green spaces, and other public infrastructures; (c) exploiting different business models and financing instruments; and finally (d) identifying the desirable scenario that will address the municipality's objectives and priorities.

Considering the final sustainability score for each scenario, one can select the best one that meets expectations and plans of the municipality or the public authority having jurisdiction, in-line with the local sustainability objectives and priorities, or the owner's intent (e.g., an authority that manages public buildings). The results can be easily communicated to the decision-makers to document the current state, summarise the proposed strategies of the final plan and illustrate the anticipated improved sustainability performance. Once a decision is taken to proceed with implementation, the concept will have to be elaborated in more detail including a cost-benefit analysis, exploit different business models and financing instruments, issue tenders and conclude with a contract. Following implementation, the local tools are ready to be used to assess whether the goals and objectives have been met, document actual progress for improving sustainability and monitor progress towards the performance targets. The results should be properly publicized and communicated so that they gain visibility and acceptance.

\subsection{Training System}

To further facilitate the process, users are also supported by a comprehensive electronic CESBA MED Training System for self and in-house education, training and professional development on sustainability. The developed material facilitates the proper use of the method and tools, improves the knowledge base and enhances the understanding of the various sustainability issues by different target groups and stakeholders (e.g., engineers, technical staff, decision and policymakers) to set up 
and implement high quality and sustainable urban plans, and supports continuous learning [34]. The training material is organized in different modules [35], including the GF concept and the multicriteria assessment methodology, the decision-making process, case studies, the assessment criteria of the contextualized tool at building and neighbourhood scale with a detailed presentation of the KPIs along with calculation examples. The electronic training material is accessible through an open e-learning platform (https://cesba-med.research.um.edu.mt/moodle/course/index.php) and is available in different languages, e.g., Catalan, Croatian, English, French, Greek, Italian and Spanish. The educational material was successfully used during 17 national pilot training courses that were held in the participating countries with about 275 participants.

\section{Results and Discussion}

The CESBA MED system was used in the field during nine pilot studies in six countries (Table A3) to demonstrate its applicability in diverse applications at different building uses and urban areas (e.g., social housing, 19th century historic buildings), scales (e.g., a building block, a university campus and different size urban neighbourhoods) and project intents (e.g., renovations or new developments). In some cases, different renovation scenarios were also assessed and the results are also summarized in Table A3. The pilots served two main purposes. First, working together with local experts and municipalities, the goal was to develop the national versions of the tools, by selecting a suitable number of indicators, translating the tools and incorporating representative national weights for the different sustainability issues and benchmarks for normalizing the indicator values. This way, the existing default values in the national versions of the tools are ready to be fine-tuned, to better match the local characteristics (e.g., energy use intensities for the local buildings, water consumption in the area, etc.). Second, they were used as a final test phase for verifying that the selected KPIs can be realistically used in the field. The goal was to ensure that the input data are commonly available during the building and urban audits, so that the KPIs can be consistently calculated. The national pilots also revealed some interesting information on the most popular sustainability indicators that were selected by each national team, illustrating the emphasis and the priorities given by the participating municipalities.

\subsection{National Tools}

The GF Tools are available in English, while the nationally contextualized assessment tools are available in different languages (i.e., Catalan, Croatian, French, Greek, Italian and Spanish). The national tools include the same KPIs, but use a different number of categories, criteria and indicators (Table 1) that best fit in the national and local context and their sustainability priorities.

Table 1. Overview of the sustainability issues, categories and criteria-indicators used in the generic framework (GF) and the national framework tools.

\begin{tabular}{lccccccccccc}
\hline & GF & $\begin{array}{c}\text { Italy } \\
\text { (A) }\end{array}$ & $\begin{array}{c}\text { Italy } \\
\text { (B) }\end{array}$ & $\begin{array}{c}\text { France } \\
\text { (A) }\end{array}$ & $\begin{array}{c}\text { France } \\
\text { (B) }\end{array}$ & $\begin{array}{c}\text { Spain } \\
\text { (A) }\end{array}$ & $\begin{array}{c}\text { Spain } \\
\text { (B) }\end{array}$ & Malta & Greece & Croatia & Average \\
\hline Bssues & 7 & 7 & 7 & 7 & 7 & 7 & 7 & 7 & 7 & 7 & 7 \\
Categories & 25 & 15 & 18 & 8 & 8 & 19 & 21 & 11 & 16 & 15 & 15 \\
Indicators & 153 & 16 & 31 & 16 & 19 & 38 & 40 & 36 & 31 & 27 & 28 \\
KPIs & 13 & 13 & 13 & 13 & 13 & 13 & 13 & 13 & 13 & 13 & 13 \\
\hline & & & \multicolumn{7}{c}{ Building Scale } \\
\hline Issues & 7 & 7 & 7 & 7 & 7 & 7 & 7 & 7 & 7 & 7 & 7 \\
Categories & 23 & 14 & 20 & 11 & 13 & 16 & 20 & 20 & 16 & 20 & 17 \\
Indicators & 178 & 34 & 46 & 16 & 19 & 33 & 59 & 66 & 44 & 38 & 39 \\
KPIs & 16 & 16 & 16 & 16 & 16 & 16 & 16 & 16 & 16 & 16 & 16 \\
\hline
\end{tabular}


Each team selected from the pool of indicators included in the Generic Framework the ones that are most relevant according to their national sustainability priorities and are commonly encountered at regional-local issues. For example, the generic framework for the neighbourhood scale includes a total of 23 categories and 178 criteria-indicators, while the national tool in Greece uses a total of 16 categories and 44 criteria-indicators. The only core set of criteria that is mandatory and included in all national tools, are the KPIs that represent internationally recognized priorities for sustainability assessment.

According to the pilot test results, the selected number of sustainability criteria averaged 28 indicators at building scale and 39 indicators at neighbourhood scale (Table 1). The sustainability issue that has attracted more emphasis based on the number of selected indicators (Figure 7) was "B-Energy and Resources" with 32\% of the total number indicators used at building scale and "G-Social Aspects" with $26 \%$ of the total at neighbourhood scale.

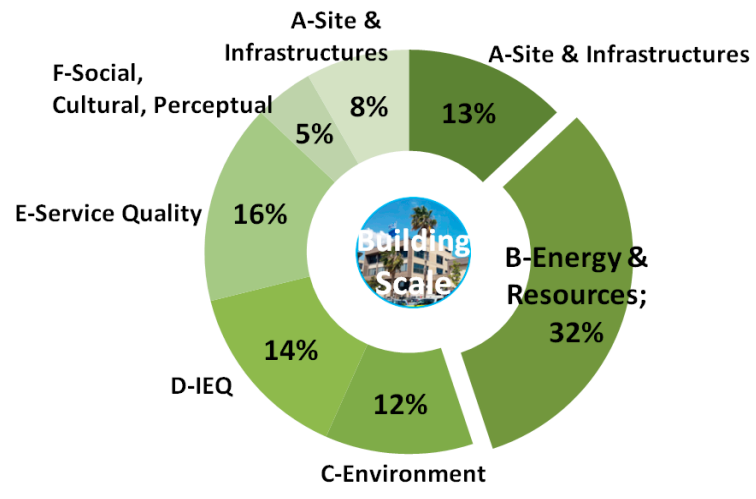

(a)

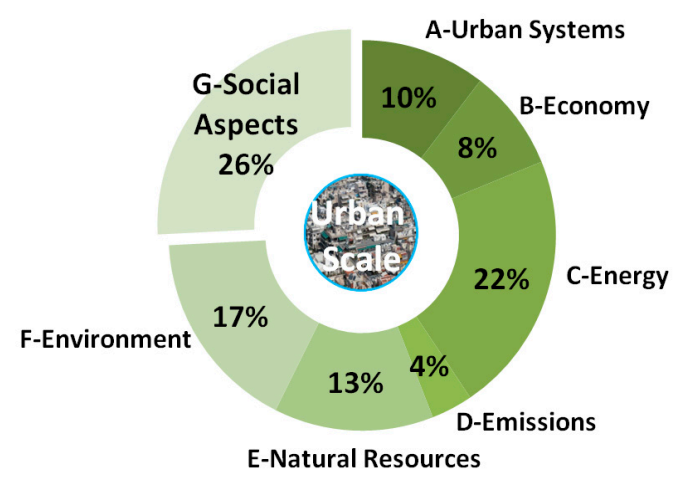

(b)

Figure 7. Overview of the average breakdown of the selected criteria-indicators used in the national tools for the seven sustainability issues for (a) the building scale; (b) the neighbourhood scale.

For each one of the selected indicators, the national teams in collaboration with local committee experts specified the local benchmarks, i.e., the values that correspond to the appropriate local excellent practice (corresponding to " +5 " in the normalized score), the minimum acceptable performance (corresponding to " 0 " in the normalized score) and below minimum standard (corresponding to " -1 " in the normalized score). This information was used to benchmark the values for each indicator and normalize them on the -1 to 5 points scale (see Section 2.2.1).

The benchmarks for the KPIs from the different regions are summarized in Table 2. The values can provide initial guidance during future developments and adaptations of similar tools in other regions. The empty cells in Table 2 (i.e., B.1.10 for embodied energy, C.3.2 for recycled solid waste, D.1.9 for ventilation rates) refer to cases with missing information. 
Table 2. Summary of the key performance indicators (KPIs) benchmarks (minimum and best values) used in the national framework tools for the building and neighbourhood scales.

\begin{tabular}{|c|c|c|c|c|c|c|c|c|c|c|c|c|c|}
\hline Code & Key Performance Indicators (KPIs) & Units & Value & Italy (A) & Italy (B) & $\begin{array}{l}\text { France } \\
\text { (A) }\end{array}$ & $\begin{array}{c}\text { France } \\
\text { (B) }\end{array}$ & $\begin{array}{c}\text { Spain } \\
\text { (A) }\end{array}$ & $\begin{array}{l}\text { Spain } \\
\text { (B) }\end{array}$ & Malta & Greece & Croatia & Average \\
\hline \multicolumn{14}{|c|}{ BUILDING SCALE } \\
\hline \multirow{2}{*}{ B.1.1 } & \multirow{2}{*}{ Primary energy use } & \multirow{2}{*}{$\mathrm{kWh} / \mathrm{m}^{2} / \mathrm{y}$} & Minimum & 80 & 140 & 48 & 140 & 225 & 292 & & 310.6 & 90 & 165.7 \\
\hline & & & Best & 30 & 23 & 0 & 0 & 70 & 58 & & 87.6 & 55 & 40.5 \\
\hline \multirow{2}{*}{ B.1.2 } & \multirow{2}{*}{ Final thermal energy use } & \multirow{2}{*}{$\mathrm{kWh} / \mathrm{m}^{2} / \mathrm{y}$} & Minimum & 70 & 80 & 40 & 130 & 22 & 75 & & 69.1 & 50 & 67.0 \\
\hline & & & Best & 20 & 10 & 0 & 30 & 12 & 20 & & 11.5 & 10 & 14.2 \\
\hline \multirow{2}{*}{ B.1.3 } & \multirow{2}{*}{ Final electrical energy use } & \multirow{2}{*}{$\mathrm{kWh} / \mathrm{m}^{2} / \mathrm{y}$} & Minimum & 30 & 23 & 40 & 140 & 75 & 70 & & 99.4 & 30 & 63.4 \\
\hline & & & Best & 20 & 5 & 0 & 0 & 20 & 30 & & 29.1 & 0 & 13.0 \\
\hline \multirow{2}{*}{ B.1.5 } & \multirow{2}{*}{ Renewables in final thermal energy use } & \multirow{2}{*}{$\%$} & Minimum & 30 & 25 & 25 & 10 & 30 & 30 & & 16 & 20 & 23.3 \\
\hline & & & Best & 100 & 50 & 100 & 100 & 100 & 100 & & 80 & 90 & 90.0 \\
\hline \multirow{2}{*}{ B.1.6 } & \multirow{2}{*}{ Renewables in final electrical energy use } & \multirow[b]{2}{*}{$\%$} & Minimum & 40 & 35 & 10 & 10 & 40 & 40 & & 20 & 5 & 25.0 \\
\hline & & & Best & 100 & 75 & 200 & 100 & 100 & 100 & & 100 & 90 & 108.1 \\
\hline \multirow{2}{*}{ B.1.10 } & \multirow{2}{*}{ Embodied non-renewable primary energy } & \multirow{2}{*}{$\mathrm{MJ} / \mathrm{m}^{2}$} & Minimum & 2500 & & 180 & 900 & & & & 6230 & 14 & 1964.8 \\
\hline & & & Best & 1000 & & 90 & 504 & & & & 3000 & 3 & 919.4 \\
\hline \multirow{2}{*}{ B.4.5 } & \multirow{2}{*}{ Water consumption for indoor uses } & \multirow{2}{*}{$\mathrm{m}^{3} /$ occupant/y } & Minimum & 40 & 47 & 40 & 90 & 100 & 11 & & 6 & 5.5 & 34.2 \\
\hline & & & Best & 25 & 23 & 20 & 20 & 20 & 5 & & 1.5 & 2 & 13.8 \\
\hline \multirow{2}{*}{ C.1.3 } & & $\mathrm{kg} \mathrm{CO}_{2}$ & Minimum & 30 & 28 & 20 & 80 & 30 & 96.31 & & 7.5 & 40 & 43.1 \\
\hline & Global warming potential & eq. $/ \mathrm{m}^{2} / \mathrm{y}$ & Best & 0 & 5 & 5 & 5 & 10 & 19.26 & & 2 & 5 & 5.9 \\
\hline & & & Minimum & 50 & 14 & 0.4 & 0.4 & 15 & & & 57 & 28 & 23.5 \\
\hline$C .3 .2$ & Solid waste categories recycled & $\%$ & Best & 80 & 100 & 1 & 1 & 100 & & & 100 & 100 & 68.9 \\
\hline D.1.9 & & & Minimum & 10 & 0.35 & 0.5 & & 6 & & & 0.29 & 2.77 & 3.3 \\
\hline D.1.9 & Ventilation rate & $\mathrm{Lt} / \mathrm{s} / \mathrm{m}^{2}$ & Best & 20 & 0.49 & 0.9 & & 12 & & & 0.83 & 6 & 6.7 \\
\hline & & & Minimum & 10 & 10 & 10 & 10 & 25 & 10 & & 25 & 25 & 15.6 \\
\hline D.2.2 & Thermal comfort index & $\%$ & Best & 0 & 6 & 5 & 0 & 5 & 0 & & 5 & 5 & 3.3 \\
\hline & & & Minimum & 20 & 10.7 & 15 & 15 & 60 & 35 & & 18.9 & 7.5 & 22.8 \\
\hline G.1.4 & Uperational energy cost & $\mathrm{E} / \mathrm{m}^{-1} \mathrm{y}$ & Best & 10 & 1.75 & 5 & 5 & 40 & 10 & & 4.7 & 1.5 & 9.7 \\
\hline & Operational water cost & & Minimum & 5 & 1.55 & 10 & 13 & & 5 & & 0.59 & 0.5 & 5.1 \\
\hline G.1.5 & Operationial water cost & $\mathrm{E} / \mathrm{m}^{-1} / \mathrm{y}$ & Best & 1 & 0.7 & 3 & 2.3 & & 1 & & 0.15 & 0.2 & 1.2 \\
\hline & & & & NEIGHB & URHOOI & SCALE & & & & & & & \\
\hline & & & Minimum & 0.5 & 7 & 15 & 10 & 4 & 10 & 10 & 10 & 2 & 7.6 \\
\hline A.1.7 & Lana conservation & $\%$ & Best & 2 & 42 & 30 & 20 & 15 & 20 & 28 & 20 & 10 & 20.8 \\
\hline & Onerational eneroy cost for public buildinos & $f / m^{2} / y r$ & Minimum & 7.4 & 10 & 14 & 14 & 20 & 13.56 & 100 & 17.7 & 100 & 33.0 \\
\hline D.3.3 & 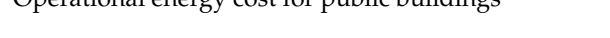 & $\mathrm{E} / \mathrm{m}^{2} / \mathrm{yr}$ & Best & 4 & 3 & 3.5 & 3.5 & 10 & 3.33 & 0 & 4.1 & 0 & 3.5 \\
\hline & Total final thermal energy consumption for buildings & $\mathrm{kWh} / \mathrm{m}^{2} / \mathrm{yr}$ & Minimum & 70 & 80 & 40 & 50 & 75 & 76.23 & 50 & 314 & 100 & 95.0 \\
\hline$C .1 .1$ & Forai & $\mathrm{KV} / \mathrm{n} / \mathrm{m}^{-} / \mathrm{yr}$ & Best & 30 & 10 & 0 & 0 & 20 & 33.8 & 0 & 21.1 & 50 & 18.3 \\
\hline & Total final electric eneroy consumption for buildinos & $\mathrm{kWh} / \mathrm{m}^{2} / \mathrm{vr}$ & Minimum & 50 & 23 & 12 & 55 & 70 & 29.85 & 25 & 64.2 & 75 & 44.9 \\
\hline 0.1 .4 & 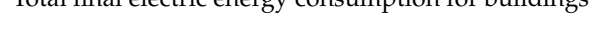 & $\mathrm{K} V \mathrm{Vn} / \mathrm{m}^{-1} \mathrm{yr}$ & Best & 20 & 5 & 0 & 5 & 20 & 10.88 & 5 & 7.9 & 50 & 13.8 \\
\hline & Total primary eneroy consumption for buildings & $\mathrm{kWh} / \mathrm{m}^{2} / \mathrm{yr}$ & Minimum & 322 & 72 & 40 & 140 & 225 & 152 & 50 & 461.9 & 100 & 173.7 \\
\hline C.1.7 & 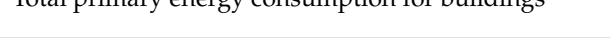 & 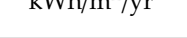 & Best & 242 & 50 & 0 & 0 & 70 & 15 & 15 & 38.2 & 70 & 55.6 \\
\hline
\end{tabular}


Table 2. Cont.

\begin{tabular}{|c|c|c|c|c|c|c|c|c|c|c|c|c|c|}
\hline & On-site renewables in total final thermal energy & & Minimum & 20 & 25 & 25 & 30 & 25 & 25 & 25 & 4 & 5 & 20.4 \\
\hline C.2.1 & consumption & $\%$ & Best & 100 & 50 & 100 & 100 & 90 & 90 & 90 & 14 & 30 & 73.8 \\
\hline \multirow{2}{*}{ C. 2.7} & \multirow{2}{*}{$\begin{array}{l}\text { On-site renewables in total final electrical energy } \\
\text { consumption }\end{array}$} & \multirow{2}{*}{$\%$} & Minimum & 20 & 35 & 25 & 35 & 15 & 15 & 35 & 1 & 20 & 22.3 \\
\hline & & & Best & 100 & 75 & 200 & 75 & 75 & 75 & 75 & 47 & 35 & 84.1 \\
\hline \multirow{2}{*}{ D.1.2 } & \multirow{2}{*}{ Total GHG Emissions from energy use in buildings } & \multirow{2}{*}{$\begin{array}{l}\mathrm{kg} \mathrm{CO} \\
\text { eq. } / \mathrm{m}^{2} / \mathrm{yr}\end{array}$} & Minimum & 22.5 & 13 & 20 & 30 & 30 & 30 & 80 & 46 & 22 & 32.6 \\
\hline & & & Best & 0 & 11 & 5 & 10 & 10 & 10 & 30 & 5 & 15 & 10.7 \\
\hline \multirow{2}{*}{ E.1.6 } & \multirow{2}{*}{ Water consumption in residential buildings } & \multirow{2}{*}{$\mathrm{m}^{3} /$ occupant/yr } & Minimum & 65 & 47.45 & 40 & 68 & 150 & 150 & 15 & 62.1 & 250 & 94.2 \\
\hline & & & Best & 61 & 23.7 & 20 & 30 & 40 & 60 & 5 & 18.6 & 100 & 39.8 \\
\hline \multirow{2}{*}{ E.1.7 } & \multirow{2}{*}{ Water consumption in public buildings } & \multirow{2}{*}{$\mathrm{m}^{3} / \mathrm{m}^{2}$} & Minimum & 1 & 1.3 & 5 & 1.1 & 15 & 15 & & 0.65 & 5 & 5.5 \\
\hline & & & Best & 0.5 & 0.6 & 2 & 0.4 & 5 & 5 & & 0.33 & 3 & 2.1 \\
\hline \multirow{2}{*}{ F.1.3 } & \multirow{2}{*}{$\begin{array}{l}\text { Recharge of groundwater through permeable } \\
\text { paving/landscaping }\end{array}$} & \multirow{2}{*}{$\%$} & Minimum & 20 & 40 & 20 & 20 & 20 & 20 & 20 & 15 & 20 & 21.7 \\
\hline & & & Best & 40 & 60 & 70 & 100 & 70 & 70 & 100 & 80 & 80 & 74.4 \\
\hline \multirow{2}{*}{ F.2.3 } & \multirow{2}{*}{ Ambient air quality (PM10) above acceptable limits } & \multirow{2}{*}{ days/yr } & Minimum & 35 & 35 & 30 & 30 & 15 & 15 & & 35 & 20 & 26.9 \\
\hline & & & Best & 25 & 0 & 11 & 11 & 11 & 11 & & 0 & 15 & 10.5 \\
\hline \multirow{2}{*}{ G.2.1 } & \multirow{2}{*}{ Proximity of residents to public transport } & \multirow{2}{*}{$\%$} & Minimum & 70 & 60 & 50 & 0 & 30 & 30 & 30 & 50 & 5 & 36.1 \\
\hline & & & Best & 100 & 100 & 100 & 100 & 100 & 100 & 100 & 100 & 40 & 93.3 \\
\hline \multirow[b]{2}{*}{ G.2.4 } & \multirow{2}{*}{ Pedestrian \& bicycle network } & \multirow{2}{*}{$\begin{array}{c}\mathrm{m} / 100 \\
\text { inhabitants }\end{array}$} & Minimum & 14 & 43 & 15 & 200 & 20 & 5 & 5 & 2 & 0 & 33.8 \\
\hline & & & Best & 42 & 129 & 40 & 50 & 80 & 40 & 40 & 20 & 500 & 104.6 \\
\hline \multirow{2}{*}{ G.4.2 } & \multirow{2}{*}{ Proximity of residents to key services } & \multirow{2}{*}{$\%$} & Minimum & 80 & 30 & 30 & 30 & 30 & 50 & 50 & 50 & 20 & 41.1 \\
\hline & & & Best & 100 & 80 & 100 & 100 & 80 & 100 & 100 & 90 & 70 & 91.1 \\
\hline \multirow[b]{2}{*}{ G.6.3 } & \multirow{2}{*}{$\begin{array}{l}\text { Community involvement in urban planning (qualitative } \\
\text { score) }\end{array}$} & \multirow{2}{*}{ level (score) } & Minimum & 0 & 3 & 0 & 0 & 0 & 0 & 0 & 0 & 0 & 0.3 \\
\hline & & & Best & 5 & 5 & 5 & 5 & 5 & 5 & 5 & 5 & 3 & 4.8 \\
\hline
\end{tabular}


The weights used for each one of the seven sustainability issues from 1 (less important) to 3 (most important or more relevant) defined in the national versions of the tools reflect the local priorities, policies or project intent. As summarized in Table 3, for the building scale, the sustainability issue "B-Energy and Resources" stands out as the strongest priority. Along with "C-Environment" are the two most prominent issues, averaging together $\sim 80 \%$. For the neighbourhood scale, lower weights were consistently used for "B-Economy" illustrating that once there is a commitment for sustainable development, the economic criteria have a lower priority. The sustainability issue related to "C-Energy" stands out by averaging $26.6 \%$ among all the pilots, although different regions have other priorities in terms of where they focus their efforts by allocating higher weights.

Table 3. Summary of the weights on different sustainability issues used in the national framework tools for the building and the neighbourhood scales.

\begin{tabular}{|c|c|c|c|c|c|c|c|c|c|c|}
\hline Sustainability Issues & $\begin{array}{l}\text { Italy } \\
\text { (A) }\end{array}$ & $\begin{array}{c}\text { Italy } \\
\text { (B) }\end{array}$ & $\begin{array}{c}\text { France } \\
\text { (A) }\end{array}$ & $\begin{array}{c}\text { France } \\
\text { (B) }\end{array}$ & $\begin{array}{l}\text { Spain } \\
\text { (A) }\end{array}$ & $\begin{array}{l}\text { Spain } \\
\text { (B) }\end{array}$ & Malta & Greece & Croatia & Average \\
\hline \multicolumn{11}{|c|}{ Building Scale } \\
\hline B-Energy and Resources & $58.0 \%$ & $69.8 \%$ & $72.0 \%$ & $72.0 \%$ & $62.9 \%$ & $54.9 \%$ & $31.6 \%$ & $28.5 \%$ & $51.2 \%$ & $55.7 \%$ \\
\hline C-Environment & $23.0 \%$ & $24.3 \%$ & $25.0 \%$ & $25.0 \%$ & $19.5 \%$ & $20.4 \%$ & $23.6 \%$ & $36.6 \%$ & $19.5 \%$ & $24.1 \%$ \\
\hline D-IEQ & $11.0 \%$ & $4.2 \%$ & $2.0 \%$ & $2.0 \%$ & $2.1 \%$ & $1.5 \%$ & $2.0 \%$ & $0.5 \%$ & $8.0 \%$ & $3.7 \%$ \\
\hline G-Economy & $8.0 \%$ & $1.8 \%$ & $2.0 \%$ & $2.0 \%$ & $0.8 \%$ & $0.8 \%$ & $3.1 \%$ & $11.0 \%$ & $5.5 \%$ & $3.9 \%$ \\
\hline \multicolumn{11}{|c|}{ Neighbourhood Scale } \\
\hline A-Urban Systems & $11.6 \%$ & $10.4 \%$ & $18.9 \%$ & $0.0 \%$ & $6.5 \%$ & $10.2 \%$ & $13.5 \%$ & $10.8 \%$ & $12.2 \%$ & $10.4 \%$ \\
\hline B-Economy & $1.7 \%$ & $6.6 \%$ & $5.0 \%$ & $1.8 \%$ & $9.1 \%$ & $3.6 \%$ & $1.8 \%$ & $4.2 \%$ & $4.6 \%$ & $4.3 \%$ \\
\hline C-Energy & $41.1 \%$ & $18.4 \%$ & $30.5 \%$ & $28.2 \%$ & $26.7 \%$ & $25.9 \%$ & $16.2 \%$ & $33.7 \%$ & $21.5 \%$ & $26.9 \%$ \\
\hline
\end{tabular}

Note: Cells a green highlight identify the Issues with the Highest Weight in each national tool

\subsection{Results from the Hellenic Pilot}

Greece has introduced a regulatory framework to support urban policy based on the law on spatial planning and sustainable development (L.4447/2016) and has drafted the national spatial and development strategy that includes medium- and long-term targets. Sustainable urban development strategies are implemented within 13 regional operational programmes, giving priority to regional capital cities or to functional areas with a certain size of population [36]. Urban and territorial strategies address 10 thematic objectives, including environmental protection and resource efficiency, network infrastructures in transport and energy, low-carbon economy, climate change adaptation and risk prevention, social inclusion, etc. The sustainable urban development strategies cover practically all thematic areas, while cities have launched broad and substantial public consultations in defining their strategies. In most cases, the municipalities have commissioned external experts to draft their plans due to limited human resources and expertise.

The CESBA MED pilot in Greece was performed at the Municipality of Fylis, north-west of Athens. Over the years, the municipality has exhibited genuine efforts, activities and communicated plans for improving its energy and carbon footprint, by implementing various initiatives on energy conservation and sustainable development aiming to regenerate into a thriving area. The pilot focused at a central area of the Municipal Unit of Ano Liosia, including the town hall and a school complex, covering 27.1 ha, half of which is built, and 1330 residents. There are about 360 buildings (including seven public buildings, the town hall, an indoor sports hall and five school buildings) in the selected area, $55 \%$ of which residential, $23 \%$ mixed-use and $22 \%$ non-residential buildings, dominated by low rise buildings ( $75 \%$ are one to two-storey high). 
Starting with the initial 178 indicators in the GF for the neighbourhood scale, the first screening rule was their applicability to the national conditions, resulting in 118 indicators. In consultation with the national local committee members this number of indicators was judged not to be practical for an assessment tool, so the second screening rule was to exclude those that were very difficult to define or assess during an audit, resulting in 77 indicators. Consulting with members from several municipalities trying to focus on the indicators that would be most relevant from a local authorities' point of view, along with their perception with regard to data availability, the number was reduced to 57 indicators. Finally, in close collaboration with the Municipality of Fylis, the final number of indicators was limited to 44 that have been documented with their selection rationale [37]. The sustainability issues with the highest importance (weighted at 3) were C- Energy, D- Atmospheric Emissions and G-Social Aspects, followed by B-Economy, E-Non-renewable Resources and F-Environment (weighted at 2) and relatively lower for A-Built Urban Systems (weighted at 1). The specific indicator weights, the corresponding benchmarks, the input data and information collected during the audits, along with the calculation processes and results are also documented in the national pilot reports.

The municipality's sustainability priorities address most of the issues identified in the SWOT analysis (Figure 8). They include efforts to reduce energy use and cost (e.g., renovate municipal buildings for improved energy performance, use energy-efficient public lighting), to exploit renewables for electricity generation (in part through energy communities) to cover the needs of public buildings and low-income residents. Energy communities are a partnership or legal entity between different local energy users, citizens, social organizations, local or city authorities, small and medium-sized local businesses, which enable energy consumers to produce, consume and share a part or all of its needed energy from renewables on a collective basis. Greece was the first EU-28 country that introduced comprehensive legislation on the establishment and operation of the energy communities (Law 4513/23.1.2018). Since then, about 60 energy communities have been formed around the country and several energy projects are under development.

\begin{tabular}{|c|c|}
\hline \begin{tabular}{ll} 
& \multicolumn{1}{c}{ STRENGTHS } \\
- & Location \\
- & Diversity (Land, Water) \\
- & Landscape \\
- & Humalogical indicators \\
- & International co-operations \\
- & Health, educational, transportation services \\
- & Economic growth \\
- & Improvement of life quality \\
- & Touristic - Industrial infrastructures \\
- & High RES potential, natural gas network \\
- & Support for vulnerable citizens \\
- & Political commitment (vision) for self- \\
& efficiency in energy, promotion of RES, \\
& environmental awareness)
\end{tabular} & \begin{tabular}{ll} 
& \multicolumn{1}{c}{ WEAKNESSES } \\
- & Slow urbanization \\
- & Lack of natural resources \\
- & Limited economic resources \\
- & Limited infrastructure networks (public \\
- & Spastewater treatment, sewer system) \\
- & Limited infrastructures outside town plan \\
extreme weather conditions & Limited infrastructures for environmental \\
- & protection \\
- & Unemployment \\
- & Safety of public places \\
- & Inadequate public lighting \\
& Ledestrian paths
\end{tabular} \\
\hline \begin{tabular}{ll}
\multicolumn{1}{c}{ OPPORTUNITIES } \\
- & Reduce energy cost and finance other \\
resources \\
- $\quad$ Support from central, regional administration \\
- $\quad$ Private investments \\
- $\quad$ Improve Muns \\
- $\quad$ Attract new citizens \\
- Protection and enhancement of cultural \\
heritage
\end{tabular} & \begin{tabular}{ll}
\multicolumn{1}{c}{ THREATS } \\
- $\quad$ Climate change \\
- $\quad$ Geomorphological characteristics \\
contribution to extreme weather condition \\
- Waste management \\
- $\quad$ Megradation of natural and cultural heritage \\
- More strict laws and regulations
\end{tabular} \\
\hline
\end{tabular}

Figure 8. SWOT analysis for the Hellenic pilot.

Other integral elements of the municipality's plan is to utilize the new main natural gas supply network, to install PVs and solar thermal in schools and sports facilities, to reduce $\mathrm{CO}_{2}$ emissions in the area (e.g., expand the pedestrian and low traffic roads, along with bicycle lanes, reintroduce municipal local transportation and public parking), and to engage citizens in the decision making process for the development of green areas for the urban regeneration of neighbourhoods. Self-efficiency in water, 
recycling (e.g., strengthening the collection and recycling of waste) and anti-flooding protection are secondary targets.

For sharing the detailed results, the area's characteristics and KPI values are summarized in the two-page CESBA Passport (Figure 9). For a higher-level communication of the overall sustainability performance, the results are summarized in the CESBA Certificate (Figure 9) that graphically illustrates the scores for each one of the seven sustainability issues and the resulting total sustainability score. The Passport can be used to exchange information on the common KPI performance, while the Certificate communicates how a project contributes value to the various sustainability issues.

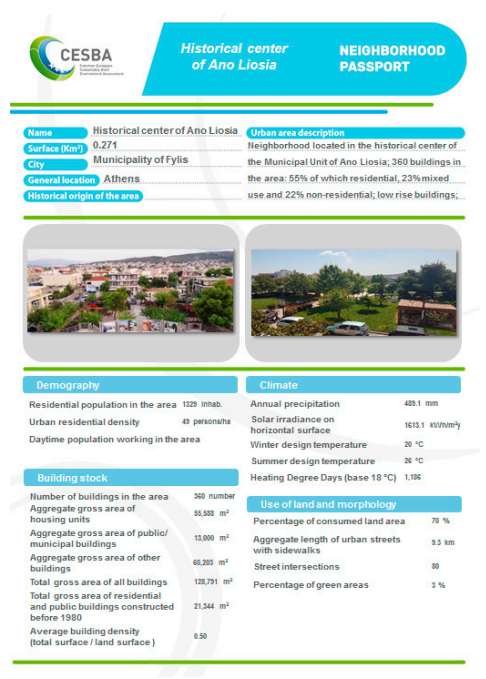

(a)

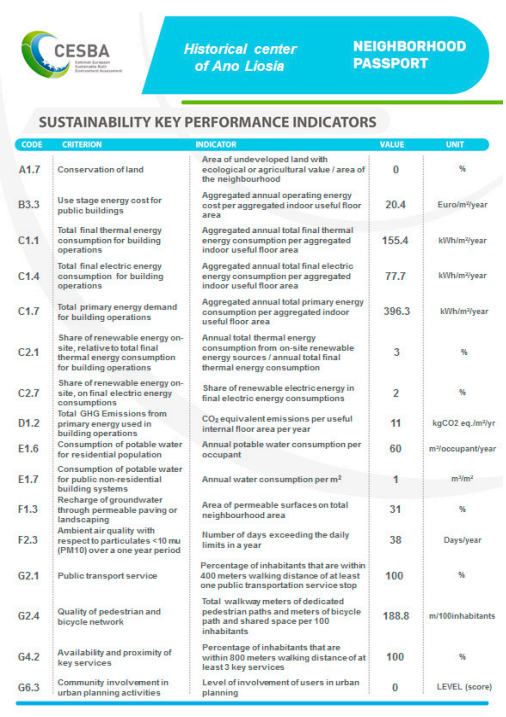

(a)

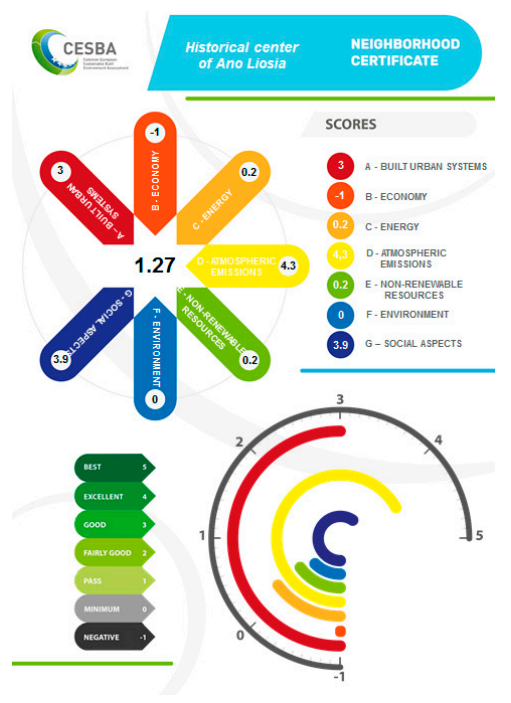

(b)

Figure 9. Representative results for the urban area assessed in the Hellenic pilot: (a) the two-page Common European Sustainable Built Environment Assessment (CESBA) Passport; (b) the CESBA Certificate.

Overall, the data collection during the audit process mandated a very close collaboration with the various municipality directorates, divisions and departments (e.g., technical services, building infrastructures, city plan and urban environment, roads and public spaces, financial, municipal assets, cleaning and recycling, green areas, etc.), access to previous studies and municipality's assessment plans, data from the national statistical authority, information from the depository of energy performance certificates, and other sources. Retrieving the input data was a time-consuming process, while sometimes provisionally available data proved difficult or even impossible to retrieve (e.g., plans or reports were not electronically archived, while hard copies were lost or misplaced). This underlines the fact that data availability is as important as data accessibility. Among the direct benefits resulting from the early stages of implementation of the CESBA MED system was the motivation and support it provided to get organized and initiate a housekeeping process within the municipality. There is value even when relevant efforts reach the point of simply identifying missing information. Following the principle that one cannot assess or manage what cannot be measured or quantified through the appropriate indicators, one can initiate practical actions for monitoring the necessary data that can prove beneficial in the future.

\section{Conclusions}

In their efforts to achieve local-regional-national and international Sustainable Development Goals (SDGs), municipalities and public authorities need flexible and easy to use methods and tools to facilitate their efforts and overcome the burdens of addressing the complexities of the issues involved. CESBA MED is a new open and flexible multicriteria assessment system structured around the UN and EU SDGs that can be used to quantify and include sustainability issues in the decision-making process. 
It supports users throughout the process in order to initiate, organize, adapt, evaluate and identify the best sustainable renovation strategies for buildings or neighbourhoods, and monitor progress towards achieving sustainability targets.

Compared to other sustainability audit and rating systems, CESBA MED offers an open-source assessment system for measuring the sustainability at building and neighbourhood scale in a harmonized approach. Cities can easily adapt it to local context by selecting and using the most suitable indicators, incorporating weighting factors that reflect local targets, priorities and policies, and have their own tailored system, which strengthens a sense of local ownership. The assessment results are comparable among cities at national and transnational levels.

At building scale, CESBA MED addresses seven sustainability issues, including: A-Site and infrastructures, B-Energy and resources, C-Environment, D-Indoor environmental quality, E-Service quality, F-Social, cultural and perceptual aspects and G-Economy, which are described and quantified with 153 sustainability criteria/indicators. Among them, 13 KPIs have been selected as mandatory indicators, which represent the priority sustainability transnational issues. At the neighbourhood scale, seven sustainability issues are addressed, including: A-Urban systems, B-Economy, C-Energy, D-Emissions, E-Natural resources, F-Environment and G-Social aspects, which are described and quantified with 178 sustainability criteria/indicators, including 16 KPIs.

The generic framework and common tools are available in English and different languages, while the assessment and rating approach have been contextualized to national (local) context for Croatia, France, Greece, Italy, Malta and Spain. Nine pilots performed in six Mediterranean countries demonstrated the applicability and adaptability of the CESBA MED system in practice for diverse applications at different scales, and verified the practical use of the KPIs in the field.

The assessment system can be used to carry out a sustainability diagnosis of buildings and neighbourhoods, to set up performance targets and to assess suitable retrofit or new development scenarios, in order to integrate sustainability in urban planning efforts. At this stage, CESBA MED does not include specific cost-related information for the various scenarios. Future work will consider the integration of relevant information since this will add practical value and facilitate the cost/benefit analysis for implementation. Furthermore, although the pilots provided sufficient confidence in the use of the overall method in the field, additional work will be necessary in order to test all the indicators included in the generic framework. In some cases, it may be necessary to reconsider some indicators. For example, A.2.4 Extent and connectivity of bicycle paths are expressed in km/1000 residents. Apparently, an area with a very low number of inhabitants will result in very high value for A.2.4, even for a small bicycle route. Although this will not be an issue in a densely populated urban area, it may be more appropriate to consider an indicator expressed as $\mathrm{km} /$ resident. With the exception of KPIs, in cases that a specific indicator may not be appropriate in local context, one can adapt the existing indicator to a more suitable one, provided that the benchmarks are also adjusted accordingly, along with the weighting factors, if necessary. In other cases, one may wish to use alternative indicators to quantify a criterion. For example, there are several indicators to evaluate environmental impacts (e.g., using the quantities of GHG emissions or the global warming potential), energy consumption (e.g., expressing the energy use intensity per unit area or per unit volume at building scale or per capita at neighbourhood scale), or thermal comfort conditions (e.g., using the standard effective temperature-SET or the predicted mean vote-PMV), etc. In principle, a method that includes several alternative indicators for some or all of the criteria may appear more flexible and advantageous. However, this is not the case for local authorities targeted by CESBA MED that need a straight forward and easy to implement tool, taking into account their limited human resources and expertise to fully understand the pros and cons of selecting and using different indicators and alternative paths. 
In this direction and to facilitate implementation, the CESBA MED system is also supported by an electronic training system that provides open access to educational material in different languages for different target groups (e.g., engineers, technical staff, decision and policymakers). The material can be used for self and in-house education, training and professional development to improve the knowledge base and understanding of the various sustainability issues and indicators, strengthen the capacity of local stakeholders to develop efficient policies and implement integrated local action plans for sustainable urban development.

The results from this work motivated the development of eight clear, actionable recommendations targeted to policymakers for promoting a new culture of the built environment in Europe [38]. Some notable good practices are already in place, illustrating the potential applicability of CESBA MED. For example, Protocollo ITACA [30] that is an environmental label promoted by the Italian regions for the evaluation and classification of buildings, is based on the transnational building scale tool [24], the reference assessment methodology adopted by CESBA MED. Since 2004, it was accepted by the Conference of Presidents of the Italian Regions and has been contextualised and used at local level by several Italian regions. Since 2015, Protocollo ITACA is the Italian national standard for the assessment of the sustainability of buildings and it is legally binding. Similar statutory audit obligations and regulatory actions for buildings may be adopted in other countries to help implement the European initiative level(s), and extended for neighbourhoods, cities and regions. Along these lines, the City Council of Sant Cugat del Vallès in Spain is using the CESBA MED method in the sustainable development of new buildings and urban areas. For example, during the design phase of new urban areas, developers are required to provide the appropriate data to calculate the CESBA MED indicators, in order to assess their proposals.

Future work will focus on extending the CESBA MED approach to regions and possibly national scales. The ambition is to facilitate and improve the effectiveness and impact of action plans and policies, towards a sustainable future for all.

Author Contributions: Conceptualization, A.M. and CESBA MED partners; methodology, A.M. and CESBA MED partners; software (Hellenic), K.G.D., S.K., C.A.B. and E.G.D.; Software, A.M., S.K., iiSBE and CESBA MED partners; formal analysis, E.B., C.A.B., K.G.D., E.G.D., S.K. and A.M.; investigation (Hellenic), C.A.B., K.G.D., E.G.D. and S.K.; data curation, C.A.B., E.B., K.G.D., E.G.D., S.K., A.M. and CESBA MED partners; writing-original draft, C.A.B.; writing-review and editing, C.A.B., K.G.D., E.G.D., S.K., A.M. and E.B.; visualization, C.A.B.; supervision (Hellenic), C.A.B.; project technical coordinator, A.M.; funding acquisition, A.M. and CESBA MED partners.

Funding: This research was co-funded by the European Regional Development Fund and national authorities, grant number INTERREG MED 2014-20 990; The APC was also funded by the same sources.

Acknowledgments: The work was performed in the frame of the European project CESBA MED (https://cesbamed.interregmed.eu) in a collaborative effort of 12 European organizations from 7 countries, coordinated by the City of Torino, Italy and A. Moro, iiSBE Italia as the technical coordinator of the work. The project was part of the Interreg Mediterranean programme (INTERREG MED 2014-20 990) co-financed by the European Regional Development Fund and national authorities. This paper reflects the views only of the authors who have made every effort to prepare this material for the benefit of the public in light of current and available information. It does not represent the opinion of the European Union. Neither the European Union institutions and bodies nor the authors may be held responsible for the use which may be made of the information contained therein.

Conflicts of Interest: The authors declare no conflict of interest. The funders had no role in the design of the study; in the collection, analyses, or interpretation of data; in the writing of the manuscript, or in the decision to publish the results. 


\section{Appendix A}

Table A1. Sustainability issues, categories and indicators in the Common European Sustainable Built Environment Assessment for Mediterranean Cities (CESBA MED) generic frameworks for building scale [27].

\begin{tabular}{ll}
\hline \multicolumn{1}{c|}{ Issues } & \multicolumn{1}{c}{ Building Scale } \\
\hline & \multicolumn{1}{c}{ Categories } \\
\cline { 2 - 3 } & $\begin{array}{l}\text { A.1-Site Regeneration and Development } \\
\text { A.1.3 Reforestation for carbon sequestration, soil stability and biodiversity (expert assessment, score); A.1.4 Development or maintenance of wildlife } \\
\text { corridors (expert assessment, score); A.1.5 Remediation of contaminated soil, groundwater or surface water (expert assessment, score); A.1.6 Shading of } \\
\text { building(s) by deciduous trees (\%); A.1.7 Use of vegetation to provide ambient outdoor cooling (ratio of total vegetated surface area by total site area); A.1.8 } \\
\text { Use of native plant types (\%); A.1.9 Provision of public open spaces (\% of land within the site); A.1.10 Provision and quality of children's play areas (expert } \\
\text { assessment, score); A.1.11 Facilities for small-scale food production for residential occupants (expert assessment, score); A.1.12 Provision and quality of } \\
\text { bicycle pathways and parking (expert assessment, score); A.1.13 Provision and quality of walkways for pedestrian use (expert assessment, score) }\end{array}$ \\
\cline { 2 - 3 } & A.2-Urban Design
\end{tabular}

A-Site and Infrastructures
A.2.1 Efficiency of land use through development density (\%); A.2.2 Need for commuting transportation through provision of mixed uses at site (expert assessment, score); A.2.3 Impact of orientation on the passive solar potential of building (expert assessment, score); A.2.4 Impact of site and building orientation on natural ventilation during warm seasons (wind pressure differential in Pa); A.2.5 Impact of site and building orientation on natural ventilation during cold seasons (wind pressure differential in $\mathrm{Pa}$ )

\section{A.3-Project Infrastructures and Services}

A.3.1 Supply, storage and distribution of surplus thermal energy amongst buildings (\%); A.3.2 Supply, storage and distribution of surplus PV electrical energy amongst buildings (\%); A.3.3 Supply, storage and distribution of surplus hot water amongst buildings (\%); A.3.4 Supply, storage and distribution of surplus rainwater and greywater amongst buildings (\%); A.3.5 Provision of facility to produce energy from solid waste (expert assessment, score); A.3.6 Provision of solid waste collection and sorting services (expert assessment, score); A.3.7 Composting and re-use of organic sludge (expert assessment, score); A.3.8 Provision of split grey/potable water services (\%); A.3.9 Provision of surface water management system (expert assessment, score); A.3.10 On-site treatment of rainwater, storm water and greywater (expert assessment, score); A.3.11 On-site treatment of liquid sanitary waste (\%); A.3.12 Provision of on-site communal transportation systems (expert assessment, score); A.3.13 Provision of on-site parking facilities for private vehicles (\%); A.3.14

Connectivity of roadways (Mean distance between intersections, m); A.3.15 Provision of access roads and facilities for freight or delivery (expert assessment, score); A.3.16 Provision and quality of exterior lighting (expert assessment, score) 
Table A1. Cont.

\section{B.1-Life Cycle Non-Renewable Energy}

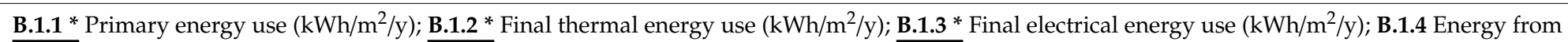
renewables to total primary energy (\%); B.1.5 * Renewables in final thermal energy use (\%); B.1.6 ${ }^{*}$ Renewables in final electrical energy use (\%); B.1.7 Use of renewable energy for all building operations $\left(\mathrm{kWh} / \mathrm{m}^{2} / \mathrm{y}\right) ; \mathbf{B} .1 .8$ Use of non-renewable energy for all building operations $\left(\mathrm{kWh} / \mathrm{m}^{2} / \mathrm{y}\right) ; \mathbf{B} .1 .9 \mathrm{Consumption}$ of non-renewable energy for project-related transportation-commuting $\left(\mathrm{kWh} / \mathrm{m}^{2} / \mathrm{y}\right) ; \underline{\mathbf{B} .1 .10}$ * Embodied non-renewable primary energy $\left(\mathrm{MJ} / \mathrm{m}^{2} / \mathrm{y}\right)$

B-Energy and Resources

\section{B.2-Electricity Peak Demand}

B.2.1 Electrical peak demand for building operations $\left(\mathrm{W} / \mathrm{m}^{2}\right)$; B.2.2 Scheduling of building operations to reduce peak loads on generating facilities $\left(\mathrm{W} / \mathrm{m}^{2}\right)$

\section{B.3-Materials}

B.3.1 Re-use of suitable existing structures (\%); B.3.2 Protection of materials during construction phase (expert assessment, score); B.3.3 Efficient use of material quantities for structural and building envelope components $\left(\mathrm{kg} / \mathrm{m}^{3}\right)$; B.3.4 Use of virgin non-renewable materials (\%); B.3.5 Use of recycled materials (\%); B.3.6 Efficient use of finishing materials (\%); B.3.7 Ease of disassembly, re-use or recycling (expert assessment, score)

\section{B.4-Potable-, Rain-, Grey-Water}

B.4.1 Embodied water in original construction materials $\left(\mathrm{Lt} / \mathrm{m}^{3}\right)$; B.4.2 Water consumption for indoor uses $\left(\mathrm{m}^{3} / \mathrm{m}^{2} / \mathrm{y}\right)$; B.4.3 Use of water for irrigation

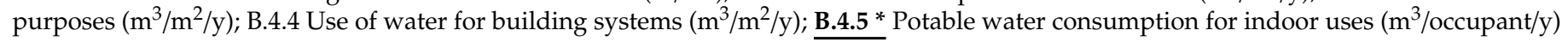

\section{C.1-Greenhouse Gas Emissions}

C.1.1 Emissions from embodied energy in original construction materials $\left(\mathrm{kgCO}_{2-\mathrm{eq}} / \mathrm{m}^{2}\right) ;$ C.1.2 Emissions from embodied energy in construction materials used for maintenance or replacement $\left(\mathrm{kgCO}_{2-\mathrm{eq}} / \mathrm{m}^{2}\right)$; C.1.3* Global Warming Potential $\left(\mathrm{kgCO}_{2-\mathrm{eq}} / \mathrm{m}^{2} / \mathrm{y}\right)$

\section{C.2-Other Atmospheric Emissions}

C.2.1 Emissions of ozone-depleting substances during facility operations (leaks $\left.\mathrm{CFC}_{\mathrm{eq}} \mathrm{g} / \mathrm{m}^{2} / \mathrm{y}\right) ; \mathrm{C} .2 .2$ Acidifying emissions during facility operations $\left(\mathrm{SO}_{2}\right.$ eq

\section{C.3-Solid and Liquid Wastes}

C.3.1* Construction and demolition waste during life cycle $\left(\mathrm{kg} / \mathrm{m}^{2}\right) ;$ C.3.2 Solid waste categories recycled (\%); C.3.3 Liquid effluents from building operations transported off the site $\left(\mathrm{m}^{3} / \mathrm{y}\right)$

\section{C.4-Impacts on Project Site}

C.4.1 Recharge of groundwater through permeable paving or landscaping (\%); C.4.2 Changes in biodiversity on the site (expert assessment, score); C.4.3 Adverse wind conditions at grade around tall buildings (expert assessment, score) 
Table A1. Cont.

\begin{tabular}{|c|c|}
\hline & C.5-Other Local and Regional Impacts \\
\hline & $\begin{array}{l}\text { C.5.1 Impact of building on access to daylight or solar energy potential of adjacent property (\%); C.5.2 Impact of construction process on local residents and } \\
\text { commercial facility users (expert assessment, score); C.5.3 Impact of building occupancy on peak load capacity of public transportation (\%); C.5.4 Impact of } \\
\text { private vehicles used by building occupants on peak load capacity of local road system (\%); C.5.5 Potential for project operations to contaminate nearby } \\
\text { water aquifer or wetland (m); C.5.6 Annual thermal changes to lake water or sub-surface aquifers }\left({ }^{\circ} \mathrm{C}\right) \text {; C.5.7 Contribution to Heat Island Effect from roofing, } \\
\left.\text { landscaping and paved areas (variance }{ }^{\circ} \mathrm{C}\right) ; \text { C.5.8 Atmospheric light pollution caused by project exterior lighting }(\%)\end{array}$ \\
\hline \multirow{8}{*}{$\begin{array}{l}\text { D-Indoor } \\
\text { Environmental } \\
\text { Quality (IEQ) }\end{array}$} & D.1-Indoor Air Quality and Ventilation \\
\hline & 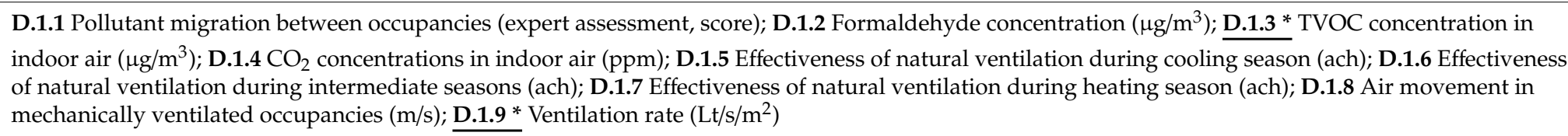 \\
\hline & D.2-Air Temperature and Humidity \\
\hline & $\begin{array}{l}\text { D.2.1 Time outside of thermal comfort range (\%); D.2.2* Thermal comfort index (PPD \%); D.2.3 Appropriate air temperature and relative humidity in } \\
\text { mechanically cooled occupancies (expert assessment, score); D.2.4 Appropriate air temperature in naturally ventilated occupancies (expert assessment, } \\
\text { score) }\end{array}$ \\
\hline & D.3-Daylight and Illumination \\
\hline & D.3.1 Appropriate daylighting in primary occupancy areas (DF \%); D.3.2 Control of glare from daylighting (max ratio of contrast) \\
\hline & D.4-Noise and Acoustics \\
\hline & $\begin{array}{l}\text { D.4.1 Noise attenuation through the exterior envelope (STC); D.4.2 Transmission of facility equipment noise to primary occupancies (NRC); D.4.3 Noise } \\
\text { attenuation between primary occupancy areas (STC) }\end{array}$ \\
\hline \multirow{4}{*}{ E-Service Quality } & E.1-Safety and Security \\
\hline & $\begin{array}{l}\text { E.1.1 Risk to occupants and facilities from fire (expert assessment, score); E.1.2 Risk to occupants and facilities from flooding (expert assessment, score); E.1.3 } \\
\text { Risk to occupants and facilities from earthquake (expert assessment, score); E.1.4 Risk to occupants from incidents involving biological or chemical } \\
\text { substances (expert assessment, score); E.1.5 Maintenance of core building functions during power outages (days); E.1.6 Personal security for building users } \\
\text { during normal operations (expert assessment, score) }\end{array}$ \\
\hline & E.2-Functionality and Efficiency \\
\hline & $\begin{array}{l}\text { E.2.1 Appropriateness of type of facilities for occupant needs (expert assessment, score); E.2.2 Suitability of interior layout(s) for required functions (expert } \\
\text { assessment, score); E.2.3 Appropriateness of space for required functions (expert assessment, score); E.2.4 Exterior access and unloading facilities for freight } \\
\text { or delivery (expert assessment, score); E.2.5 Service quality and efficiency of vertical or horizontal transportation systems (expert assessment, score); E.2.6 } \\
\text { Spatial efficiency (\%); E.2.7 Volumetric efficiency (\%) }\end{array}$ \\
\hline
\end{tabular}


Table A1. Cont.

\begin{tabular}{|c|c|}
\hline & E.3-Controllability \\
\hline & $\begin{array}{l}\text { E.3.1 Effectiveness of facility management control system (expert assessment, score); E.3.2 Capability for partial operation of facility technical systems } \\
\text { (expert assessment, score); E.3.3 Degree of local control of lighting systems }\left(\mathrm{m}^{2}\right) ; \text { E.3.4 Degree of personal control of technical systems by occupants (expert } \\
\text { assessment, score) }\end{array}$ \\
\hline & E.4-Flexibility and Adaptability \\
\hline & $\begin{array}{l}\text { E.4.1 Ability for building operator or tenant to modify facility technical systems (expert assessment, score); E.4.2 Potential for horizontal or vertical extension } \\
\text { of structure (expert assessment, score); E.4.3 Adaptability constraints imposed by structure or floor-to-floor heights (expert assessment, score); E.4.4 } \\
\text { Adaptability constraints imposed by building envelope and technical systems (expert assessment, score); E.4.5 Adaptability to future changes in type of } \\
\text { energy supply (expert assessment, score) }\end{array}$ \\
\hline & E.5-Operation and Maintenance \\
\hline & $\begin{array}{l}\text { E.5.1 Operating functionality and efficiency of key facility systems (expert assessment, score); E.5.2 Adequacy of the building envelope for maintenance of } \\
\text { long-term performance (expert assessment, score); E.5.3 Durability of key materials (expert assessment, score); E.5.4 Maintenance management plan (expert } \\
\text { assessment, score); E.5.5 On-going monitoring and verification of performance (expert assessment, score); E.5.6 Retention of as-built documents (expert } \\
\text { assessment, score) }\end{array}$ \\
\hline \multirow{6}{*}{$\begin{array}{l}\text { F-Social, Cultural, } \\
\text { Perceptual }\end{array}$} & F.1-Social Aspects \\
\hline & $\begin{array}{l}\text { F.1.1 Universal access on-site and within the building (expert assessment, score); F.1.2 Access to direct sunlight from living areas of dwelling units (\%); F.1.3 } \\
\text { Visual privacy in principal areas of dwelling units (\%); F.1.4 Access to private open space from dwelling units (\%) }\end{array}$ \\
\hline & F.2-Culture and Heritage \\
\hline & $\begin{array}{l}\text { F.2.1 Compatibility of urban design with local cultural values (expert assessment, score); F.2.2 Provision of public open space compatible with local cultural } \\
\text { values (expert assessment, score); F.2.3 Impact of the design on existing streetscapes (expert assessment, score); F.2.4 Use of traditional local materials and } \\
\text { techniques (\%); F.2.5 Maintenance of the heritage value - external (expert assessment, score); F.2.6 Maintenance of the heritage value-internal (expert } \\
\text { assessment, score) }\end{array}$ \\
\hline & F.3. Perceptual Aspects \\
\hline & $\begin{array}{l}\text { F.3.1 Impact of tall structure(s) on existing view corridors (expert assessment, score); F.3.2 Quality of views from tall structures (expert assessment, score); } \\
\text { F.3.3 Sway of tall buildings in high wind conditions (m); F.3.4 Perceptual quality of site development (expert assessment, score); F.3.5 Aesthetic quality of } \\
\text { facility exterior (expert assessment, score); F.3.6 Aesthetic quality of facility interior (expert assessment, score); F.3.7 Access to exterior views from interior } \\
\text { (expert assessment, score) }\end{array}$ \\
\hline \multirow{2}{*}{ G-Economy } & G.1-Operational Cost \\
\hline & $\begin{array}{l}\text { G.1.1 Construction } \operatorname{cost}\left(€ / \mathrm{m}^{2}\right) \text {; G.1.2 Operating and maintenance cost }\left(€ / \mathrm{m}^{2}\right) \text {; G.1.3 Life-cycle cost }\left(€ / \mathrm{m}^{2}\right) \text {; G.1.4 }{ }^{*} \text { Operational energy cost }\left(€ / \mathrm{m}^{2} / \mathrm{y}\right) ; \underline{\text { G.1.5 }} \text { * } \\
\text { Operational water } \operatorname{cost}\left(€ / \mathrm{m}^{2} / \mathrm{y}\right) \text {; G.1.6 Investment risk (expert assessment, score); G.1.7 Affordability of residential rental or cost levels }(\%)\end{array}$ \\
\hline
\end{tabular}

${ }^{*}$ Key Performance Indicator (KPI). 
Table A2. Sustainability issues, categories and indicators in the CESBA MED generic frameworks for neighbourhood scale [28]

\begin{tabular}{|c|c|}
\hline & NEIGHBOURHOOD SCALE \\
\hline Issues & Categories \\
\hline \multirow{4}{*}{ A-Urban Systems } & A.1-Urban Structure and Form \\
\hline & $\begin{array}{l}\text { A.1.1 Concentration of lots to the total area (\%); A.1.2 Urban compactness }\left(\mathrm{m}^{3} / \mathrm{m}^{2}\right) \text {; A.1.3 Building plot ratios (\%); A.1.4 Residential density (inhabitants/hectare); } \\
\text { A.1.5 Urban street canyons H/W aspect ratio (\%); A.1.6 Homogeneity of the urban fabric (\%); A.1.7* Conservation of land (\%) }\end{array}$ \\
\hline & A.2-Transportation Infrastructure \\
\hline & $\begin{array}{l}\text { A.2.1 Walking distance to public transport for area residents (\% of residential buildings located within 500m); A.2.2 Walking distance to public transport for area } \\
\text { workers and students (\%); A.2.3 Extent and connectivity of pedestrian streets and walkways (\%); A.2.4 Extent and connectivity of bicycle paths separated from } \\
\left.\text { vehicular traffic (km/1000 residents); A.2.5 Cyclomatic complexity of the street network (-); A.2.6 Connectivity of the street network (number } / \mathrm{km}{ }^{2}\right) \text {; A.2.7 Street } \\
\text { network connection and accessibility (\%); A.2.8 Scale of the street network (m); A.2.9 On-street and indoor parking spaces relative to local population (\%); A.2.10 } \\
\text { Intermodality facilities (expert assessment, score) }\end{array}$ \\
\hline \multirow{6}{*}{ B-Economy } & B.1-Economic Structure and Value \\
\hline & $\begin{array}{l}\text { B.1.1 Affordability of building property (\%); B.1.2 Affordability of building rental (\%); A.1.3 Long-term risk for capital investments (\%); B.1.4 Impact of land values on } \\
\text { adjacent areas (\%); B.1.5 Impact of construction and operations on the local economy (\%); B.1.6 Percent of building vacancies (\%) }\end{array}$ \\
\hline & B.2-Economic Activity \\
\hline & $\begin{array}{l}\text { B.2.1 Income equity for households (GINI index 0-1); A.2.2 Percent of average annual per-capita income of residents to region's total (\%); A.2.3 Employment rate (\%); } \\
\text { A.2.4 Economic viability of local commercial businesses (\%); A.2.5 Economic contribution from tourism activity (€/resident) }\end{array}$ \\
\hline & B.3-Cost and Investment \\
\hline & $\begin{array}{l}\text { B.3.1 Adequacy of social housing (expert assessment, score); B.3.2 Public contribution in residential retrofitting investments }(\%) \text {; B.3.3* Operational energy costs for } \\
\text { public buildings }\left(€ / \mathrm{m}^{2} / \mathrm{y}\right) ; \text { B.3.4 Levels of total public and private investment }(€ / \text { resident) }\end{array}$ \\
\hline \multirow[b]{3}{*}{ C-Energy } & C.1-Non-Renewable Energy \\
\hline & $\begin{array}{l}\text { C.1.1 } * \text { Total final thermal energy consumption for all buildings }\left(\mathrm{kWh} / \mathrm{m}^{2} / \mathrm{y}\right) ; \text { C.1.2 Total final thermal energy consumption for residential buildings }\left(\mathrm{kWh} / \mathrm{m}^{2} / \mathrm{y}\right) ; \text { C.1.3 } \\
\text { Total final thermal energy consumption for non-residential buildings }\left(\mathrm{kWh} / \mathrm{m}^{2} / \mathrm{y}\right) \text { : C.1.4 }{ }^{*} \text { Total final electrical energy consumption for all buildings }\left(\mathrm{kWh} / \mathrm{m}^{2} / \mathrm{v}\right) \text { : C.1.5 }\end{array}$ \\
\hline & 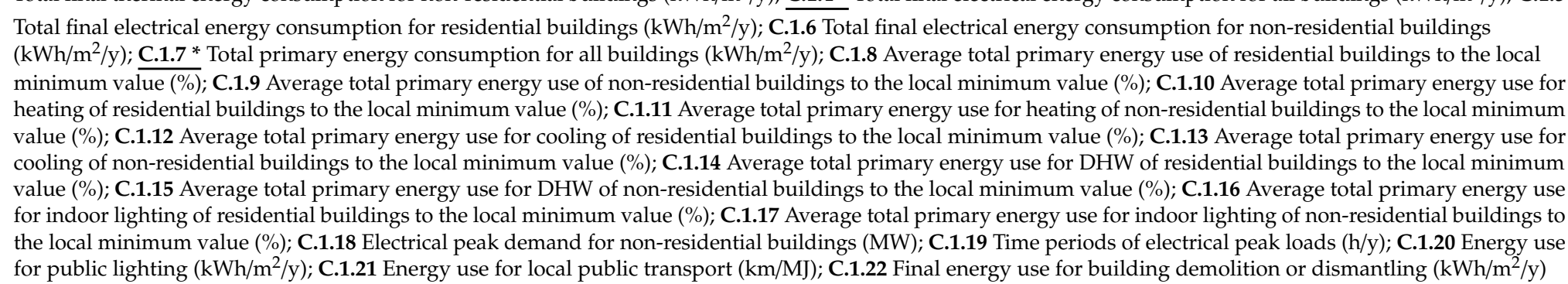 \\
\hline
\end{tabular}


Table A2. Cont.

\section{C.2-Renewable and Clean Energy}

C.2.1* On-site renewables in total final thermal energy consumption for all buildings (\%); C.2.2 On-site renewables in total final energy consumption for residential buildings (\%); C.2.3 On-site renewables in total final energy consumption for non-residential buildings (\%); C.2.4 On-site renewables in total primary energy consumption for all buildings (\%); C.2.5 On-site renewables in total primary energy consumption for residential buildings (\%); C.2.6 On-site renewables in total primary energy consumption for non-residential buildings (\%); C.2.7* On-site renewables in total final electrical energy consumption for all buildings (\%); C.2.8 Aggregated electrical energy generation from renewables located on public properties (MWh/y); C.2.9 Aggregated electrical energy generation from renewables located on private properties (MWh/y); C.2.10 Aggregated electrical energy generated from renewables that is exported from the local area (MWh/y); C.2.11 Percentage of electrical energy use from renewables (\%); C.2.12 Aggregated thermal energy generation from renewables located on public properties (MWh/y); C.2.13 Aggregated thermal energy generation from renewables located on private properties (MWh/y); C.2.14 Aggregated thermal energy generated from renewables that is exported from the local area (MWh/y)

\section{C.3-District Networks and Storage}

C.3.1 Waste heat recovery from building operations (\%); C.3.2 Mid- and long-term thermal storage capacity of geothermal energy sinks (\%); C.3.3 Mid-term storage of electrical energy (GWh)

\section{D.1-Atmospheric Pollution}

D.1.1 GHG emissions from embodied energy in materials used for construction, maintenance or replacements (tons $\mathrm{CO}_{2}$ eq./1000 $\mathrm{m}^{2}$ ); D.1.2 $^{*}$ Total GHG emissions

D-Emissions

from energy use in buildings $\left(\mathrm{kgCO}_{2} \mathrm{eq} . \mathrm{m}^{2} / \mathrm{y}\right)$; D.1.3 Aggregate ozone-depleting emissions from 3-year building operations (tons $\mathrm{CO}_{2}$ eq./1000 m²); D.1.4 Aggregate of acidifying-emissions from 5-year building operations ( $\mathrm{kg} \mathrm{CO}_{2} \mathrm{eq} . / 1000 \mathrm{~m}^{2}$ ); D.1.5 Aggregate $\mathrm{GHG}_{\mathrm{H}}$ emissions from the use of private vehicles (tons $\mathrm{CO}_{2}$ eq./y); D.1.6 Aggregate GHG emissions from the use of public transport (tons $\mathrm{CO}_{2}$ eq./10,000 passengers); D.1.7 Total GHG Emissions from buildings, private and public mobility (tons $\mathrm{CO}_{2}$ eq./1000 residents)

\section{E.1-Potable-, Rain-, Grey-Water}

E.1.1 Availability of a public municipal water supply (\%); E.1.2 Provision of split grey/potable water services in buildings (\%); E.1.3 Re-use of rainwater in residential buildings (\%); E.1.4 Re-use of rainwater in non-residential buildings (\%); E.1.5 Re-use of storm water (\%); E.1.6 * Water consumption in residential buildings $\left(\mathrm{m}^{3} /\right.$ occupant/y); E.1.7 *Water consumption in non-residential buildings $\left(\mathrm{m}^{3} / \mathrm{m}^{2} / \mathrm{y}\right) ;$ E.1.8 Consumption of potable water for irrigation purposes $\left(\mathrm{m}^{3} / 1000 \mathrm{~m}^{2} / \mathrm{y}\right) ;$ E.1.9 Intensity of water purification treatment $\left(\mathrm{kWh} / \mathrm{m}^{3} / \mathrm{y}\right)$

E-Natura

Resources

\section{E.2-Solid and Liquid Waste}

E.2.1 Proximity of residents to solid waste and recycling collection points (\%); E.2.2 Separate collection and disposal of solid waste and recycling (\%); E.2.3 Solid waste from construction and demolition projects retained in the area for re-use or recycling (\%); E.2.4 Solid waste from residents' activities and facility operations sent out of the area for re-use, recycling or disposal (\%); E.2.5 Composting and re-use of organic sludge (\%); E.2.6 Public wastewater that is disposed or treated (\%); E.2.7 Liquid effluents from building operations that are exported (\%); E.2.8 Potential for building operations to contaminate nearby bodies of water (expert assessment, score); E.2.9 Cumulative annual thermal changes to lake water or sub-surface aquifers (expert assessment, score)

\section{E.3-Usage, Retention and Maintenance}

E.3.1 Consumption of non-renewable material resources for building construction or renovation (Tons/1000 $\mathrm{m}^{2}$ ); E.3.2 Efficient use of materials for construction of infrastructures (Tons $/ 1000 \mathrm{~m}^{2}$ ); E.3.3 Reused or recycled materials for building construction or renovation (\%); E.3.4 Adaptive re-use of existing buildings and structures (\%); E.3.5 Preservation and maintenance of existing buildings and structures (expert assessment, score); E.3.6 Heritage preservation of existing buildings (expert assessment, score) 
Table A2. Cont.

\section{F.1-Environmental Impacts}

F.1.1 Impact of construction activities on natural environment and land preservation (expert assessment, score); F.1.2 Impact of construction activities or landscaping on soil stability or erosion (expert assessment, score); F.1.3 ${ }^{*}$ Recharge of groundwater through permeable paving/landscaping (\%); F.1.4 Impacts on local biodiversity (expert assessment, score); F.1.5 Urban heat island effects ( $\left.{ }^{\circ} \mathrm{C}\right)$; F.1.6 Impact on access to daylight or solar energy potential of contiguous buildings (\%); F.1.7 Impact of local building user population on peak load capacity of public transport system (\%); F.1.8 Impact of private vehicles used by local population on peak load capacity of the local road network (expert assessment, score); F.1.9 Atmospheric light pollution from exterior lighting systems of building (Night sky brightness cd/ $\left.\mathrm{m}^{2}\right)$; F.1.10 Atmospheric light pollution from public lighting (Night sky brightness $\mathrm{cd} / \mathrm{m}^{2}$ ); F.1.11 Albedo of building and paving surfaces (number);

\section{F.2-Outdoor Environmental Quality}

F.2.1 Ambient air quality (PM2.5) above acceptable limits (days/y); F.2.2 Ambient air quality (PM2.5) above acceptable limits over a week (days/week); F.2.3 * Ambient air quality (PM10) above acceptable limits (days/y); F.2.4 Ambient air quality (PM10) above acceptable limits over a week (days/week); F.2.5 Ambient air quality (CO) above acceptable limits (days/y); F.2.6 Ambient air quality $\left(\mathrm{O}_{3}\right)$ above acceptable limits (days/y); F.2.7 Olfactory air quality (odours) in the area (number of anecdotal reports/y); F.2.8 Adverse wind conditions at grade around low-rise buildings (expert assessment, score); F.2.9 Adverse wind conditions at grade around high-rise reports/y); F.2.8 Adverse wind conditions at grade around low-rise buildings (expert assessment, score); F.2.9 Adverse wind conditions at grade around high-rise
buildings (expert assessment, score); F.2.10 Area above acceptable ambient daytime noise limits (\%); F.2.11 Area above acceptable ambient nigh time noise limits (\%); F.2.12 Summer thermal comfort conditions (SET); F.2.13 Winter thermal comfort conditions (SET)

F-Environment

F.3-Ecosystems and Landscape

F.3.1 Green zones and recreation areas availability (\%); F.3.2 Proximity to green zones and recreation areas (m); F.3.3 Green zones and recreation areas density (\%); F.3.4 Contamination of soil and water resources in undeveloped land (\%); F.3.4 Surface water management to prevent flooding (expert assessment, score); F.3.6 Tree shade open area coverage (\%); F.3.7 Green roofs (\%); F.3.8 Vegetated walls and other building surfaces $\left(\mathrm{m}^{2}\right)$; F.3.9 Presence or potential for wildlife corridors (expert assessment, score); F.3.10 Ecological diversity (expert assessment, score); F.3.11 Ecological sensitivity (expert assessment, score); F.3.12 Walking or bicycling nature trails (km/1000 residents); F.3.13 Condition of surface freshwater systems (expert assessment, score); F.3.13 Condition of groundwater and subsurface aquifers (expert assessment, score); F.3.14 Viability of adjacent wetlands and urban marine environments (expert assessment, score)

\section{G.1-Accessibility and Safety}

G.1.1 Building accessibility by physically disabled persons (\%); G.1.2 Sidewalks and other pedestrian paths accessibility by physically disabled persons (\%); G.1.3 Barrier-free accessibility in outdoor public areas (\%); G.1.4 Accessibility to and use of public transport for physically disabled persons (\%); G.1.5 Adequacy of signage and traffic safety measures (expert assessment, score)

\section{G.2-Traffic and Mobility Services}

G.2.1 * Proximity of residents to public transport (\%); G.2.2 Availability of car sharing services (\%); G.2.3 Measures to limit passing through car and truck traffic

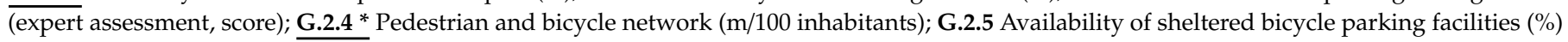

G.3.1 Coverage of broadband communication network (\%); G.3.2 Access to a broadband communication network (\%)

\section{G.4-Facilities and Services}

G.4.1 Availability and proximity of key food and retail services (\%); G.4.2 * Proximity of residents to key services (\%); G.4.3 Proximity of residents to a primary school (\%); G.4.4 Proximity of residents to a secondary school (\%); G.4.5 Proximity of residents to children's' play facilities (\%); G.4.6 Proximity of residents to leisure facilities (\%); G.4.7 Proximity of residents to indoor sports facilities (\%) 
Table A2. Cont.

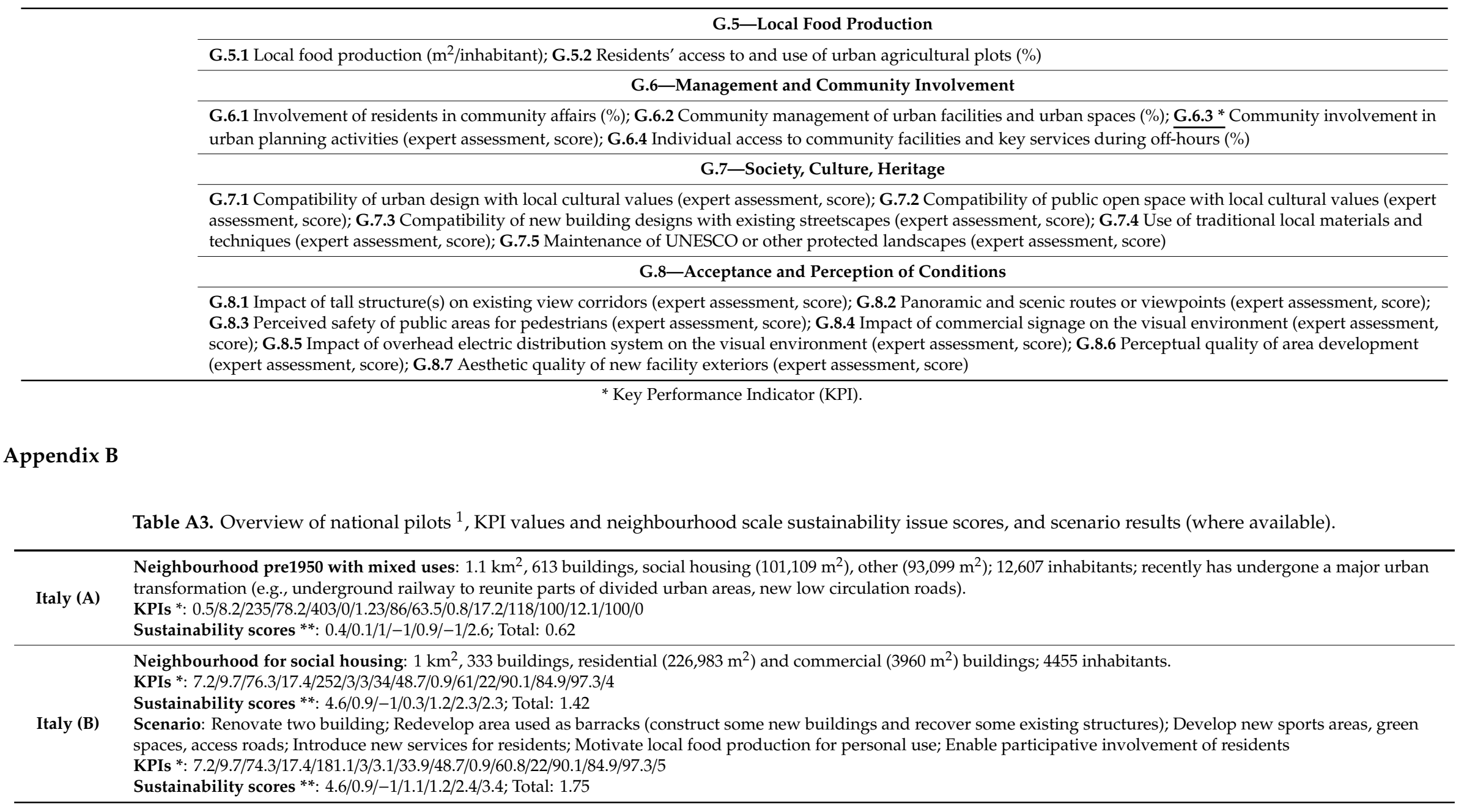


Table A3. Cont.

\begin{tabular}{|c|c|}
\hline France (A) & $\begin{array}{l}\text { Urban renewal area: } 1.2 \mathrm{~km}^{2}, 3600 \text { residential buildings, } 1372 \text { social housing; } 11,000 \text { inhabitants. } \\
\text { KPIs *: 7/NA/NA/NA/NA/NA/NA/NA/50/NA/NA/8/97/63.4/100/3.5 } \\
\text { Sustainability scores **: -1/NA/NA/NA/1/NA/3.8; Total: } 0.57\end{array}$ \\
\hline France (B) & $\begin{array}{l}\text { New development of an industrial and urban brownfield: } 0.08 \mathrm{~km}^{2}, 23 \text { buildings, residential }\left(95,000 \mathrm{~m}^{2}\right) \text {, office }\left(25,000 \mathrm{~m}^{2}\right) \text { and commercial }\left(8600 \mathrm{~m}^{2}\right) \text { buildings; } 4700 \\
\text { inhabitants. } \\
\text { KPIs *: } 0 / 5.9 / 41 / 7 / 53 / 32 / 25 / 8 / 62 / 8 / 30 / 11.5 / 80 / 94 / 100 / 3 \\
\text { Sustainability scores **: NA/3.8/1/5/2.2/4.1/3.8; Total: } 3.30\end{array}$ \\
\hline Spain (A) & $\begin{array}{l}\text { Building block with mixed uses: } 0.013 \mathrm{~km}^{2}, 17 \text { buildings, } 19 \text { th and early } 20 \text { th century residential }\left(56,750 \mathrm{~m}^{2}\right) \text {, office }\left(2468 \mathrm{~m}^{2}\right) \text { and retail }\left(5736 \mathrm{~m}^{2}\right) \text { buildings, with Art Nouveau } \\
\text { architecture; } 766 \text { inhabitants, } 1750 \text { daytime working population. } \\
\text { KPIs }{ }^{*}: 0 / 16.6 / 54.8 / 53.3 / 172.2 / 1.2 / 0.73 / 26.4 / 35.8 / 0.58 / 0.12 / 5 / 100 / 115.5 / 100 / 2 \\
\text { Sustainability scores }{ }^{* *}: 1.3 / 1.4 /-1 / 0.9 / 5 / 1.7 / 4.8 ; \text { Total: } 1.64 \\
\text { Scenario: Form a cooperative among building owners to finance renovations, Recover space for public use, Reduce loads (insulate building envelopes, green roofs) and energy } \\
\text { costs, Exploit renewables (building-integrated PVs), Use efficient equipment (heat pumps for heating, cooling, DHW), Reduce emissions, Remove access barriers to buildings, } \\
\text { Improve IEQ } \\
\text { KPIs }{ }^{*}: 4.0 / 10.0 / 20.1 / 75 / 75 / 40 / 40 / 20 / 25 / 0.10 / 10 / 0 / 100 / 250 / 100 / 3 \\
\text { Sustainability scores }{ }^{* *}: 1.9 / 4.4 / 2.8 / 2.5 / 5.0 / 1.7 / 4.8 ; \text { Total: } 3.08\end{array}$ \\
\hline Spain (B) & $\begin{array}{l}\text { Neighbourhood with mixed uses: } 0.44 \mathrm{~km}^{2}, 625 \text { buildings, residential }\left(560,673 \mathrm{~m}^{2}\right) \text {, office }\left(554,869 \mathrm{~m}^{2}\right) \text { and retail }\left(537,203 \mathrm{~m}^{2}\right) \text { buildings; } 11,060 \text { inhabitants. } \\
\text { KPIs *: } 2.7 / 7.1 / 47.5 / 33.3 / 124.6 / 1.6 / 0.03 / 31.2 / 49.1 / 4.9 / 15.4 / 6.7 / 100 / 16.2 / 100 / 2 \\
\text { Sustainability scores **: } 1.9 / 2.2 /-1 /-1 / 4.4 / 1.8 / 3.8 ; \text { Total: } 1.02 \\
\text { Scenario: Expand pedestrian streets; Encourage light mobility (reduce emissions, noise); Expand green and leisure areas (reduce heat island effects) } \\
\text { KPIs *: } 2.7 / 7.1 / 47.5 / 33.3 / 1.6 / 0.9 / 0.03 / 31.2 / 49.1 / 4.9 / 15.4 / 6.7 / 100 / 30 / 100 / 4 \\
\text { Sustainability scores }{ }^{* *}: 2.1 / 2.2 /-1 / 0.1 / 4.4 / 2.1 / 4.4 ; \text { Total: } 1.60\end{array}$ \\
\hline Malta & $\begin{array}{l}\text { University Campus: } 0.27 \mathrm{~km}^{2}, 30 \text { buildings, office }\left(194,674 \mathrm{~m}^{2}\right) \text { and retail }\left(1296 \mathrm{~m}^{2}\right) \text { buildings; Daytime population } 14,000 \text { people. } \\
\text { KPIs } * 27.9 / \mathrm{NA} / 16.1 / 103.2 / 233.8 / 64 / 16.4 / 76.5 / \mathrm{NA} / 7.9 / 18.3 / 12.6 / 60 / 26 / 100 / 3 \\
\text { Sustainability scores **: } 2.7 / 2.7 / 1.8 / 0.3 / 3.1 / 0.5 / 2.8 ; \text { Total: } 1.85\end{array}$ \\
\hline Greece & $\begin{array}{l}\text { Neighbourhood historical centre with mixed uses: } 0.271 \mathrm{~km}^{2}, 360 \text { buildings, residential }\left(55,588 \mathrm{~m}^{2}\right) \text {, office }\left(13,000 \mathrm{~m}^{2}\right) \text { and retail }\left(60,203 \mathrm{~m}^{2}\right) \text { buildings; } 1329 \text { inhabitants. } \\
\text { KPIs *: 0/20.4/155.4/77.7/396.3/3/2/11/60/1/31/38/100/188.8/100/0 } \\
\text { Sustainability scores **: } 3 /-1 / 0.2 / 4.3 / 0.2 / 0 / 3.9 ; \text { Total: } 1.27 \\
\text { Scenario: Form an energy community and work towards power generation from renewables to cover needs for municipal buildings and low income households; Exploit } \\
\text { renewables (roof PVs on public buildings); Use efficient equipment (high performance heat pumps for heating, cooling); Connect all buildings to new natural gas central } \\
\text { network; Replace all lighting fixtures in public spaces with LED; Increase recycling collection bins; Reintroduce municipality transportation with two lines; Improve safety } \\
\text { KPIs *: 0/1.9/132.0/72.1/341.4/4/6/6.5/59.5/0.6/31/38/100/188.8/100/1 } \\
\text { Sustainability scores **: } 3.1 /-1 / 2.2 / 4.8 / 1.9 / 0 / 4.1 ; \text { Total: } 2.24\end{array}$ \\
\hline
\end{tabular}




\section{References}

1. Eurostat. Energy Statistical Country Datasheets; European Commission, DG Energy, Unit A4: Brussels, Belgium, 2019; Available online: https://ec.europa.eu/eurostat/web/energy/data/energy-balances (accessed on 10 July 2019).

2. Dodd, N.; Donatello, S.; Garbarino, E.; Gama-Caldas, M. Identifying Macro-Objectives for the Life Cycle Environmental Performance and Resource Efficiency of EU Buildings; Joint Research Centre, European Commission: Seville, Spain, 2015; 116p, Available online: https:/www.construction-products.eu/application/files/1615/ 2466/0561/151222_Resource_Efficient_Buildings_Macro_objectives_WP_Final_version.pdf (accessed on 10 July 2019).

3. Construction and Demolition Waste (CDW); Waste streams, Environment, European Commission: Brussels, Belgium; Available online: https://ec.europa.eu/environment/waste/construction_demolition.htm (accessed on 10 July 2019).

4. Regional Policy; Urban Development; European Commission: Brussels, Belgium; Available online: https: //ec.europa.eu/regional_policy/en/policy/themes/urban-development/ (accessed on 15 October 2019).

5. Circular Economy Action Plan; Environment, European Commission: Brussels, Belgium; Available online: https://ec.europa.eu/environment/circular-economy/index_en.htm (accessed on 7 October 2019).

6. 2030 Climate \& Energy Framework; Climate Strategies \& Targets; European Commission: Brussels, Belgium; Available online: https://ec.europa.eu/clima/policies/strategies/2030_en (accessed on 8 October 2019).

7. Clean Energy for all Europeans Package; Energy; European Commission: Brussels, Belgium; Available online: https://ec.europa.eu/energy/en/topics/energy-strategy-and-energy-union/clean-energy-all-europeans (accessed on 7 October 2019).

8. Saheb, Y.; Shnapps, S.; Paci, D. From Nearly-Zero Energy Buildings to Net-Zero Energy Districts; EUR 29734 EN; Publications Office of the European Union: Luxembourg, Luxembourg, 2019.

9. De Pascali, P.; Bagaini, A. Energy Transition and Urban Planning for Local Development. A Critical Review of the Evolution of Integrated Spatial and Energy Planning. Energies 2019, 12, 35. [CrossRef]

10. UN Sustainable Development Goals; United Nations: New York, NY, USA, 2019; Available online: https: //www.un.org/sustainabledevelopment/sustainable-development-goals/ (accessed on 10 July 2019).

11. COM. 739 Communication from the Commission to the European Parliament, the Council, the European Economic and Social Committee and the Committee of the Regions; European Commission: Strasbourg, France, 22 November 2016; Available online: https://eur-lex.europa.eu/legal-content/EN/TXT/PDF/?uri=CELEX:52016DC0739\& from $=\mathrm{EN}$ (accessed on 7 October 2019).

12. Urban Agenda for the EU; European Commission: Brussels, Belgium; Available online: https://ec.europa.eu/ futurium/en/urban-agenda (accessed on 5 October 2019).

13. Lafortune, G.; Zoeteman, K.; Fuller, G.; Mulder, R.; Dagevos, J.; Schmidt-Traub, G. The 2019 SDG Index and Dashboards Report for European Cities (prototype version). Sustainable Development Solutions Network (SDSN) and the Brabant Center for Sustainable Development (Telos), 2019. Available online: https://www.sustainabledevelopment.report/news/first-ever-sdg-index-and-dashboards-report-foreuropean-cities/ (accessed on 16 October 2019).

14. Balaras, C.A.; Dascalaki, E.G. Chapter 9.1-Energy Audits of Existing Buildings. In Handbook of Energy Efficiency in Buildings, 1st ed.; Asdrubali, F., Desideri, U., Eds.; Butterworth-Heinemann Elsevier: Oxford, UK, 2018; pp. 677-713.

15. Barbano, G.; Eßig, N.; Mittermeier, P.; Orova, M.; Beagon, P.; Claudi, L.; Gómez-Salcedo, J.F.; Kiedaisch, F. Definition of Sustainable Key Performance Indicators; NEWTREND Project, H2020 Program; European Commission: Brussels, Belgium, 2016; Available online: http://newtrend-project.eu/wp-content/uploads/ 2015/11/NewTREND_WP2_D2.2_KPI_GB04_V5.2.pdf (accessed on 16 October 2019).

16. Lawrence, T.; Balaras, C.A.; Means, J.K. A Comparison of How Sustainability and Green Building Standards are Being Adopted into Building Construction Codes within the United States and the EU. In Proceedings of the International Conference on Sustainable Built Environment SBE 16-Strategies-Stakeholders-Success Factors, Hamburg, Germany, 8-11 March 2016; pp. 42-51. Available online: https://pure.tugraz.at/ws/ portalfiles/portal/3050178/SBE16Hamburg_ConferenceProceedings.pdf (accessed on 8 October 2019). 
17. ANSI/ASHRAE/USGBC/IES Standard 189.1-Standard for the Design of High Performance Green Buildings Except Low-Rise Residential Buildings; ASHRAE: Atlanta, GA, USA, 2017; Available online: https://www.ashrae.org/ standards-research--technology/standards--guidelines (accessed on 8 October 2019).

18. Mattoni, B.; Guattari, C.; Evangelisti, L.; Bisegna, F.; Gori, P.; Asdrubali, F. Critical review and methodological approach to evaluate the differences among international green building rating tools. Renew. Sustain. Energy Rev. 2018, 82, 950-960. [CrossRef]

19. Chethana, I.M.; Illankoon, S.; Tam, V.W.Y.; Le, K.N.; Shen, L. Key credit criteria among international green building rating tools. J. Clean. Prod. 2017, 164, 209-220. [CrossRef]

20. He, Y.; Kvan, T.; Liu, M.; Li, B. How green building rating systems affect designing green. Build. Environ. 2018, 133, 19-31. [CrossRef]

21. Sicignano, E.; Di Ruocco, G.; Stabile, A. Quali-A Quantitative Environmental Assessment Method According to Italian CAM, for the Sustainable Design of Urban Neighbourhoods in Mediterranean Climatic Regions. Sustainability 2019, 11, 4603. [CrossRef]

22. Level(s)_Taking Action on the Total Impact of the Construction Sector, Joint Research Centre (JRC); Publications Office of the European Union: Luxembourg, Luxembourg, 2019; Available online: https://ec.europa.eu/ environment/eussd/pdf/LEVELS_REPORT_en.pdf (accessed on 7 October 2019).

23. Martos, A.; Pacheco-Torres, R.; Ordóñez, J.; Jadraque-Gago, E. Towards successful environmental performance of sustainable cities: Intervening sectors. A review. Renew. Sustain. Energy Rev. 2016, 57, 479-495. [CrossRef]

24. iiSBE. International Initiative for a Sustainable Built Environment; Ottawa, ON, Canada, 2007; Available online: www.iisbe.org (accessed on 8 October 2019).

25. Balaras, C.A.; Dascalaki, E.G.; Droutsa, K.G.; Moro, A.; Barbano, G.; Chanussot, L.; Cazas, J.; Zidar, M.; Bačan, I.; et al. D3.1.1 Transnational Indicators and Assessment Methods for Buildings and Urban Areas; CESBA MED Consortium: Marseille, France, 2017; 409p, Available online: https://cesba-med.interreg-med.eu/fileadmin/user_upload/Sites/ Efficient_Buildings/Projects/CESBA_MED/D3.1.1_Indicators_CESBA_MED_Final-V1.5_June_2017.pdf (accessed on 8 October 2019).

26. Moro, A. D3.3.1 Testing Protocol-Assessment Methodology; CESBA MED Consortium: Marseille, France, 2017; 100p, Available online: https://cesba-med.interreg-med.eu/results/deliverables/ (accessed on 16 October 2019).

27. Moro, A. D3.4.1-CESBA MED SBT Building Generic Framework; CESBA MED Consortium: Marseille, France, 2019; 78p, Available online: https://cesba-med.interreg-med.eu/results/deliverables/ (accessed on 16 October 2019).

28. Moro, A. D3.4.2—CESBA MED SNT Urban Generic Framework; CESBA MED Consortium: Marseille, France, 2019; 83p, Available online: https://cesba-med.interreg-med.eu/results/deliverables/ (accessed on 16 October 2019).

29. Dodd, N.; Cordella, M.; Traverso, M.; Donatello, S. Level(s)—A common EU Framework of Core Sustainability Indicators for Office and Residential Buildings, Part 3: How to Make Performance Assessments Using Level(s); Joint Research Centre, European Commission: Seville, Spain, 2017; 211p, Available online: https://susproc.jrc.ec. europa.eu/Efficient_Buildings/docs/170816_Levels_EU_framework_of_building_indicators.pdf (accessed on 7 October 2019).

30. ITACA. Istituto per l'Innovazione e Trasparenza Degli Appalti e la Compatibilità Ambientale; Institute for Transparency of Contracts and Environmental Compatibility: Rome, Italy; Available online: http://www.itaca.org (accessed on 7 October 2019).

31. Moro, A. D3.4.3a CESBA MED KPIs—Building Scale; CESBA MED Consortium: Marseille, France, 2019; 30p, Available online: https://cesba-med.interreg-med.eu/results/deliverables (accessed on 16 October 2019).

32. Moro, A. D3.4.3b CESBA MED KPIs—Urban Scale; CESBA MED Consortium: Marseille, France, 2019; 28p, Available online: https://cesba-med.interreg-med.eu/results/deliverables (accessed on 16 October 2019).

33. Moro, A. D3.3.2 v.1.1 Model of Decision Making Process for Sustainable Urban Areas and Public Buildings; CESBA MED Consortium: Marseille, France, 2018; 15p, Available online: https://cesba-med.interreg-med.eu/results/ deliverables/ (accessed on 16 October 2019).

34. Borgaro, P. D4.2.2 v.1.4 Training System Framework; CESBA MED Consortium: Marseille, France, 2018; 26p, Available online: https://cesba-med.interreg-med.eu/results/deliverables/ (accessed on 16 October 2019).

35. Borg, R.P. D5.2.1—elearning Courses; CESBA MED Consortium: Marseille, France, 2019; 19p, Available online: https://cesba-med.interreg-med.eu/results/deliverables/ (accessed on 16 October 2019). 
36. STRAT-Board: Territorial and Urban Strategies Dashboard; Greece Country Fact Sheet; European Commission: Brussels, Belgium; Available online: https://urban.jrc.ec.europa.eu/strat-board/\#/factsheetcountry?id=EL\& name $=$ Greece $\&$ fullscreen $=$ yes (accessed on 15 October 2019).

37. Droutsa, K.G.; Balaras, C.A.; Dascalaki, E.G.; Kontoyiannidis, S. D3.3.2-GR Pilot Test in Greece, Assessment Report-Hellenic Pilot Test Results; CESBA MED Consortium: Marseille, France, 2019; 15p, Available online: https://cesba-med.interreg-med.eu/results/deliverables (accessed on 16 October 2019).

38. Torrent, L.; Wadel, G.; Sagrera, A. D5.3.1 CESBA MED Policy Paper; CESBA MED Consortium: Marseille, France, 2019; 15p, Available online: https://cesba-med.interreg-med.eu/results/deliverables (accessed on 16 October 2019).

(C) 2019 by the authors. Licensee MDPI, Basel, Switzerland. This article is an open access article distributed under the terms and conditions of the Creative Commons Attribution (CC BY) license (http://creativecommons.org/licenses/by/4.0/). 